\title{
SHEAR STRENGTH AND ARTIFICIAL AGING CHARACTERIZATION FOR SILICONE BONDING OF POLYISOBUTYLENE (PIBS) BLENDS IN RELATION TO THEIR USE AS LEAD INSULATION MATERIAL
}

\author{
A Thesis \\ Presented to the Faculty of \\ California Polytechnic State University \\ San Luis Obispo \\ In Partial Fulfillment of the Requirements \\ For the Degree \\ Master of Science in Biomedical Engineering
}

By Shawn Grening

February 2009 
(C) 2009

SHAWN GRENING

ALL RIGHTS RESERVED 


\section{COMMITTEE PAGE}

TITLE:

AUTHOR:

DATE SUBMITTED:

COMMITTEE CHAIR: Robert Crocket, Associate Professor

COMMITTEE MEMBER: L Lily Hsu Laiho, Assistant Professor

COMMITTEE MEMBER: Daniel W. Walsh, Associate Dean, College of Engineering

SHEAR STRENGTH AND ARTIFICIAL AGING

CHARACTERIZATION FOR SILICONE BONDING OF POLYISOBUTYLENE (PIBS) BLENDS IN RELATION TO THEIR USE AS LEAD INSULATION MATERIAL

Shawn Grening

May, 2009 


\section{ABSTRACT \\ SHEAR STRENGTH AND ARTIFICIAL AGING CHARACTERIZATION FOR SILICONE BONDING OF PIBS BLENDS IN RELATION TO THEIR USE AS LEAD INSULATION MATERIAL}

\section{Shawn Grening}

In order to take advantage of the properties of poly(styrene-isobutylene-styrene) PIBS and PIB based blends as lead insulation materials, they must be able to sufficiently bond to the various materials that make up the cardiac device. The bonded PIBS must be able to withstand the mechanical stress and corrosive environment of the human body due to the long term use of these devices. Based on the component requirements of lead insulation, the first objective of this study was to perform an initial screening of multiple PIBS / stainless steel / silicone adhesive combinations. The specific polymers of interest were PIBS, $10 \% 55 \mathrm{D}$ polyurethane, $10 \% 75 \mathrm{D}$ polyurethane, $10 \% \mathrm{PP}$, and a silicone control. Based on the bonding shear strength results of the initial screening, the best performing combinations were artificially aged to simulate their resistance to degradation in vivo. Each combination was subjected to both $3 \%$ hydrogen peroxide and Phosphate Buffered Saline solutions for a period of 8 weeks to test for oxidative and hydrolytic stability. Bonding shear strengths for all sample groups were tested at each 2-week period. The $10 \% 55 \mathrm{D}$ sample group had the highest mean bonding shear strength at $.5602 \mathrm{MPa}$, but to observe the aging stability of all sample groups, all combinations were used in Phase II. The phosphate buffered saline solution in Phase II caused no significant decrease in bonding shear strength for all sample groups. Alternatively, oxidation caused by the $3 \%$ hydrogen peroxide solution did significantly affect the bonding shear strengths of all sample groups (minus the silicone control). Over the 8-week period PIBS degraded 28\% and 10\%55D and 10\%75D decreased $40.0 \%$ and $30.8 \%$, respectively. $10 \% \mathrm{PP}$ degraded $32.0 \%$ and the silicone control remained relatively unchanged. 


\section{TABLE OF CONTENTS}

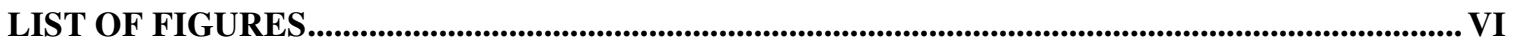

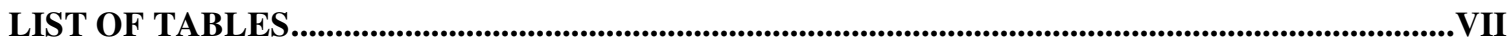

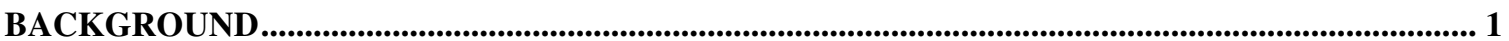

1.1. IMPLANTABLE CARDIAC RHYThM MANAGEMENT DEVICES .............................................. 1

1.1.1. Purpose

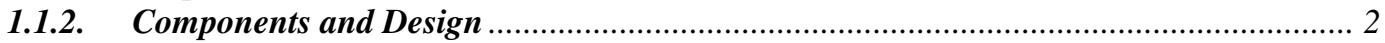

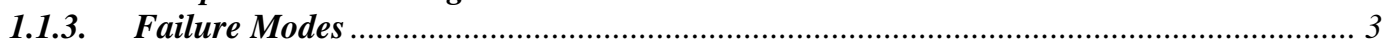

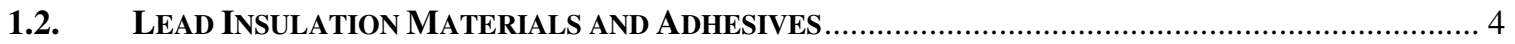

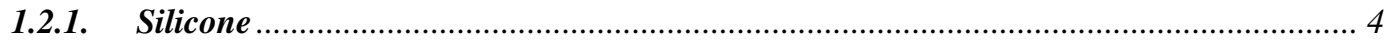

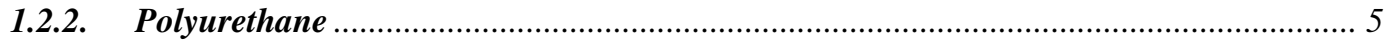

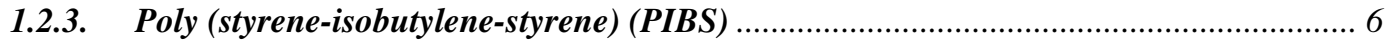

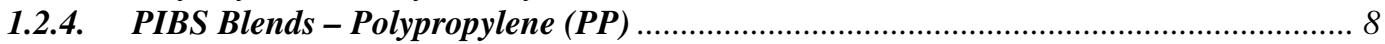

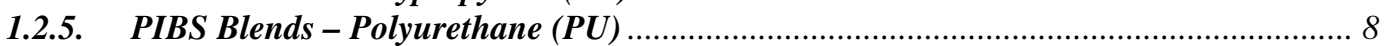

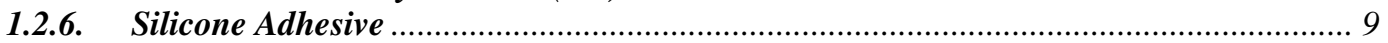

1.2.7. Primer

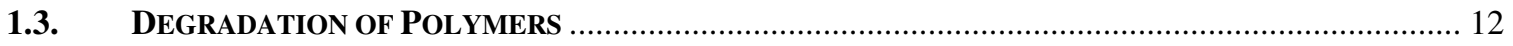

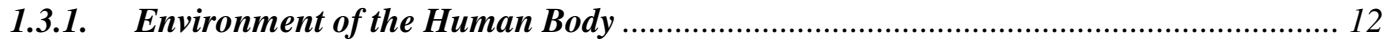

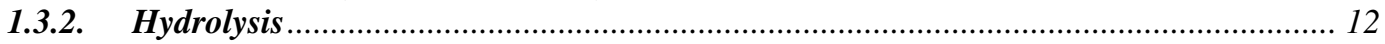

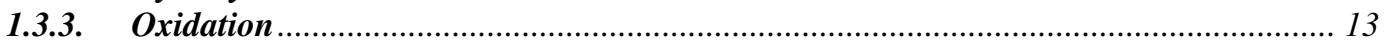

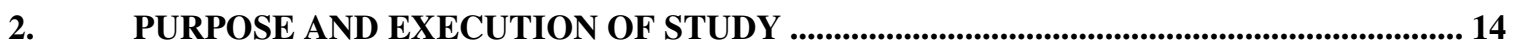

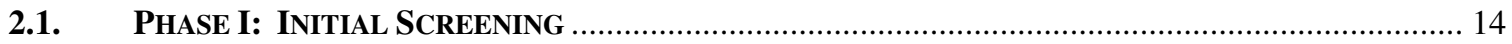

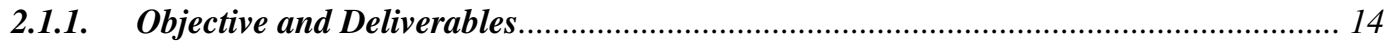

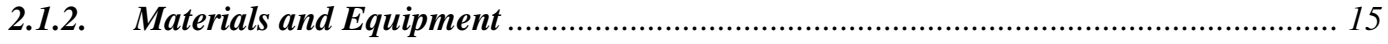

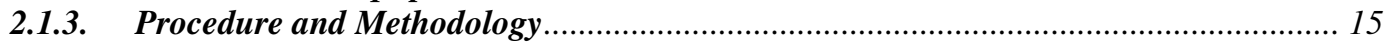

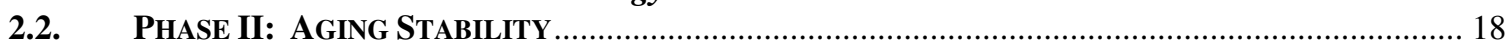

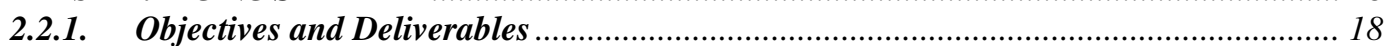

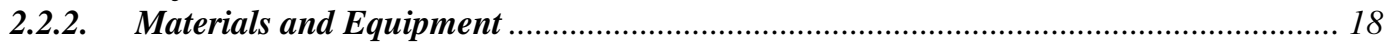

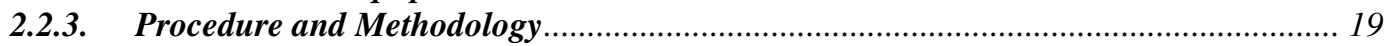

3. RESULTS ................................................................................................................................ 21

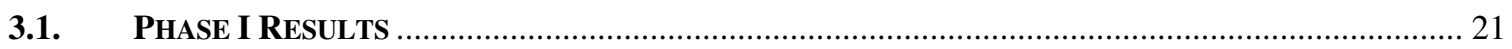

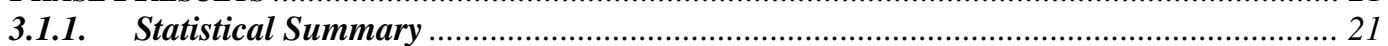

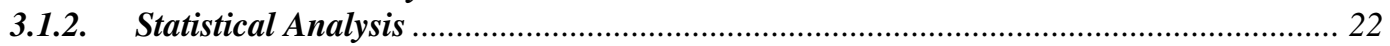

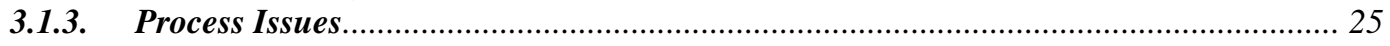

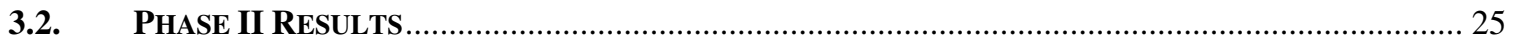

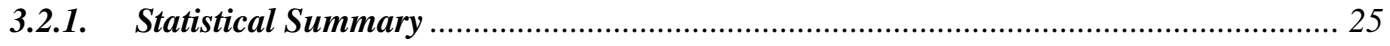

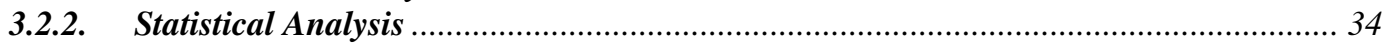

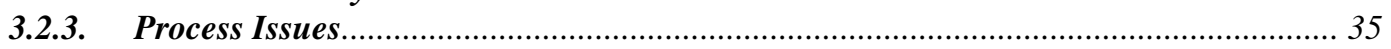

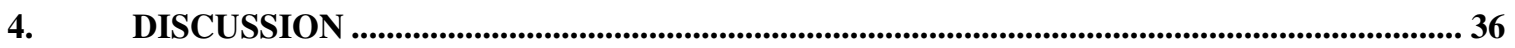

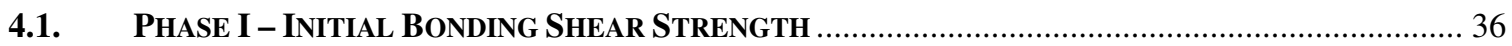

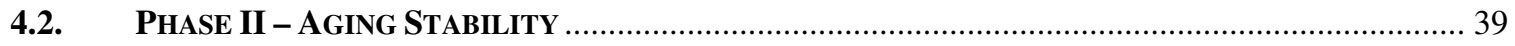

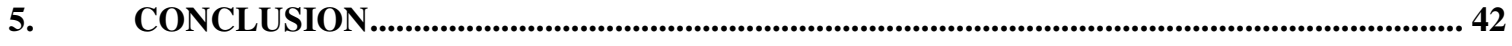

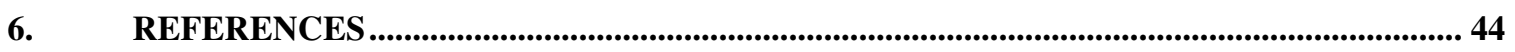

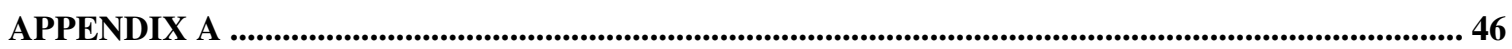




\section{LIST OF FIGURES}

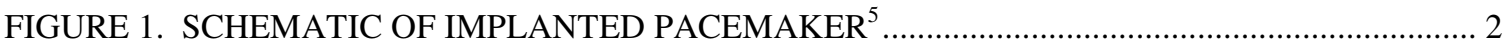

FIGURE 2. SEGMENTS OF THE POLY(STYRENE-ISOBUTYLENE-STYRENE) TRI-BLOCK COPOLYMER $^{14}$

FIGURE 3, SILANE PRIMER ADHESION PROMOTION

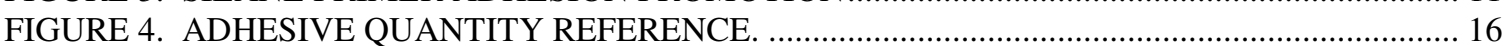

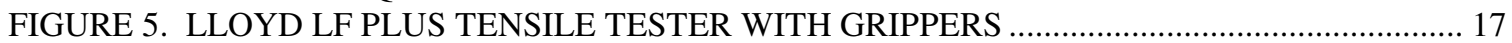

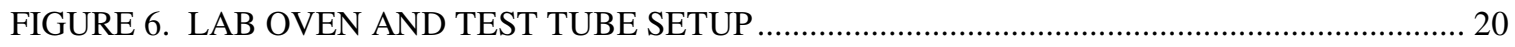

FIGURE 7. PHASE I INITIAL BONDING SHEAR STRENGTH BOX PLOTS..................................... 22

FIGURE 8. PHASE I PROBABILITY PLOT FOR EACH SAMPLE GROUP SHOWING

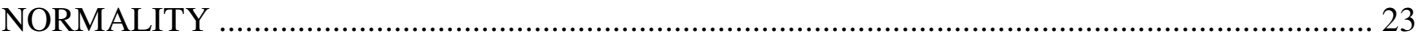

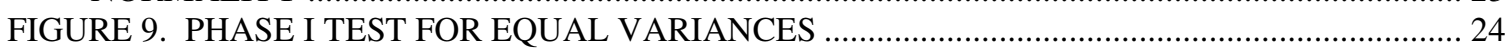

FIGURE 10. PIBS/SS BONDING SHEAR STRENGTH (MPA) VS. AGING TIME (WEEKS)

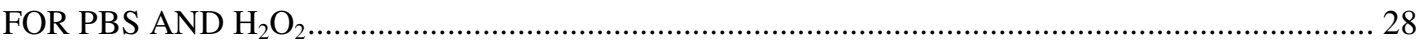

FIGURE 11. 10\%PP/SS BONDING SHEAR STRENGTH (MPA) VS. AGING TIME (WEEKS)

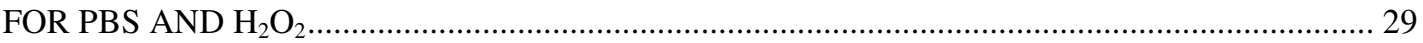

FIGURE 12. $10 \% 55 \mathrm{D} / \mathrm{SS}$ BONDING SHEAR STRENGTH (MPA) VS. AGING TIME (WEEKS)

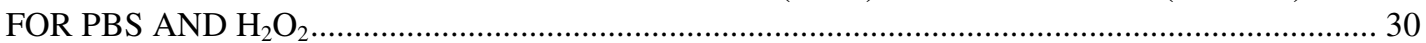

FIGURE 13. $10 \%$ 75D/SS BONDING SHEAR STRENGTH (MPA) VS. AGING TIME (WEEKS) FOR PBS AND $\mathrm{H}_{2} \mathrm{O}_{2}$

FIGURE 14. SILICONE/SS BONDING SHEAR STRENGTH (MPA) VS. AGING TIME (WEEKS) FOR PBS AND $\mathrm{H}_{2} \mathrm{O}_{2}$

FIGURE 15. WEEK 8 BOX PLOTS OF BONDING SHEAR STRENGTHS ...

FIGURE 16. WETTING ANGLE OF ADHESIVE ON SUBSTRATE SHOWING BAD AND $\mathrm{GOOD}^{27}$

FIGURE 17. INITIAL MEAN BONDING SHEAR STRENGTHS WITH RELATIVE SURFACE ENERGY VALUE.

FIGURE 18. ADHESIVE ON STAINLESS STEEL NEEDLE FOLLOWING BOND FAILURE 


\section{LIST OF TABLES}

TABLE 1 - TYPICAL PROPERTIES OF SILASTIC BIOMEDICAL GRADE ETR ELASTOMERS ${ }^{11} \ldots .5$

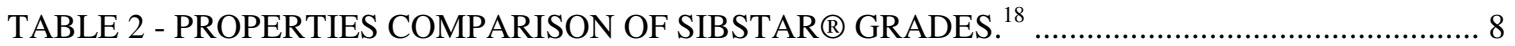

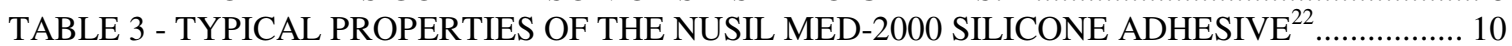

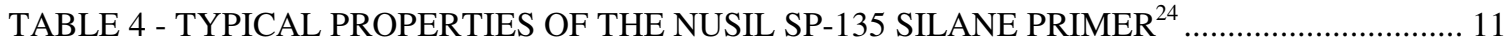

TABLE 5 - PHASE I BONDING SHEAR STRENGTH STATISTICAL SUMMARY …….................... 21

TABLE 6 - TWO SAMPLE T-TEST FOR SIGNIFICANT DIFFERENCE BETWEEN PHASE I MEAN BONDING SHEAR STRENGTHS FOR EACH GROUP …………............................ 25

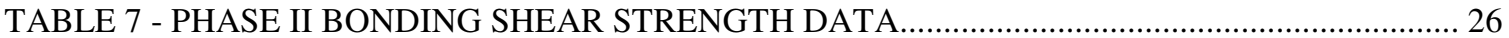

TABLE 8 - TWO SAMPLE T-TEST RESULTS FOR DIFFERENCE IN MEAN BONDING SHEAR

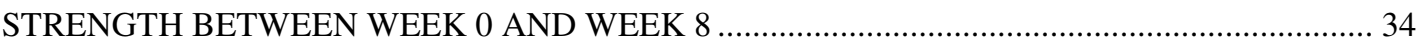

TABLE 9 - SURFACE ENERGIES OF RELEVANT MATERIALS ….................................................. 37 


\section{BACKGROUND}

\subsection{Implantable Cardiac Rhythm Management Devices}

\subsubsection{Purpose}

Patients with abnormal heart rhythms (cardiac arrhythmias) are often treated with implantable medical devices that deliver an electrical impulse to help restore their normal heart beat. The two most common devices are pacemakers and implantable cardioverter defibrillators (ICDs). The primary purpose of a pacemaker is to treat a condition called bradycardia, which is a heart rate that is too slow caused by a reduced rate of Sinoatrial Node (SA) firing. Long-term implantation is performed with minimally invasive surgery under local anesthesia and generally requires less than 45 minutes. The electrodes are placed in the heart through one of the large subclavian veins in the chest and after external testing the small generator is placed under the skin (Figure 1). Modern pacemakers are externally programmable and allow the physician to select optimum pacing modes for each patient. An ICD is a device implanted like a pacemaker that monitors the patient's heart rhythm and waits for an arrhythmia. When it detects a tachycardia (a heart rate that is too fast), the ICD delivers a high-energy electric impulse (defibrillation) that restores normal heart rhythm. If a bradycardia is detected, it can also deliver a low-energy signal similar to a pacemaker. ${ }^{1-4}$ 


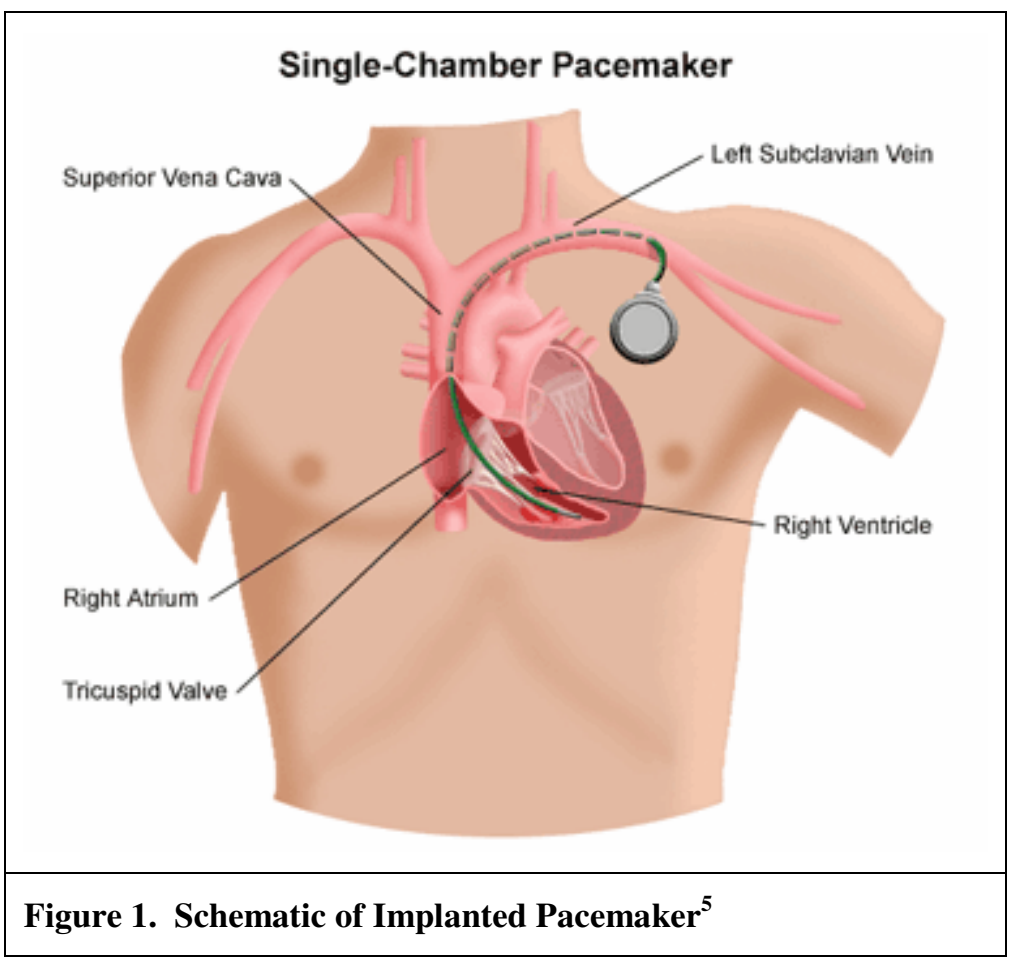

\subsubsection{Components and Design}

ICDs and pacemakers mainly consist of three main components: the generator, leads, and electrodes. All pulse generators include a power source, an output circuit, a sensing circuit, a timing circuit, and a header with a standardized connector to attach the leads. These generator components are typically hermetically sealed in a titanium casing termed "the can". Lithiumiodide batteries now power most pulse generators and have an expected service life of 5-12 years depending on the pacing parameters. Most ICD designs use two capacitors in series to achieve maximum voltage for defibrillation. Electric impulse form the generator travels down one or more ICD leads, which use a coil structure to create the high density current required for defibrillation. At the distal tip of the lead an electrode is in direct contact with the myocardium and delivers the electric pulse for pacing, defibrillation, and/or sensing. These electrodes often possess a helix or screw at the tip to avoid dislodgement. A lead is covered with non-conductive polymer insulation except for at the distal end where the electrode makes contact with the heart 
and the proximal end that connects to the generator. This lead insulation serves as a barrier to the electrical impulse supplied by the generator and the corrosive organic solvents in the body. ${ }^{1,6,7}$

\subsubsection{Failure Modes}

Generator breakdown most often occurs from the battery reaching end of life, which ceases the pacing and sensing capabilities of the device. Generator failure due to electronic or mechanical issues is extremely rare and according to most in the industry, the lead remains the "weakest link" of implantable pacing systems. ${ }^{8}$ Problems begin with the connectors and sealing rings and become even more pronounced with insulation materials. The insulation used for the lead is a major design factor affecting lead reliability. The most frequently used insulation materials are silicone, polyurethane, and fluorine-polymers (PTFE, ETFE), but no pacemaker lead insulation has been proven to have complete reliability. Due to its softness, silicone can be prone to damage from abrasion once implanted and with the pursuit for smaller diameter pacing leads, some manufacturers have failed to consider the stresses placed on the insulation material during the manufacturing process. High levels of harmful organic solvents in vivo can change the chemical structure of polyurethane, destroying its elastic properties, subjecting it to built-in stresses, and increasing the potential for failure. Insulation fracture or erosion of any insulation material causes shunting of the electrical current away from the defibrillation electrode and into the body, decreasing the affect on the arrhythmia. Insulation breakdown always requires lead replacement. $^{8,9}$ 


\subsection{Lead Insulation Materials and Adhesives}

An important task for the biomedical industry is to move toward the design of thinner, more flexible, and less thrombogenic defibrillation lead with acceptable biostability and biocompatibility.

\subsubsection{Silicone}

During the 1960's, silicone rubber became popular as an insulating material for pacemaker leads. Silicone has excellent biocompatibility and biostability, but because of its softness and low tear strength it has some drawbacks. The risk of tool damage during implantation, and abrasion in vivo requires relatively thick insulating layers producing bulky and stiff leads. Silicone surfaces also have a high wet friction coefficient that when left untreated and combined with the required thickness can lead to thrombosis and endothelial trauma.

Since silicone has historically been the most reliable lead insulation material in terms of biostability ( $>30$ years), it was used as a control in this study. Despite its mechanical shortcomings, it is not vulnerable to hydrolysis, oxidation, and other forms of degradation from the harsh organic solvents of the body. ${ }^{9}$ The specific silicone elastomer tubing used in this study was SILASTIC BioMedical Grade ETR Q7-4780, which is a two-part, enhanced-tear-resistant (ETR) silicone elastomer that consists of dimethyl and methylvinyl siloxane copolymers and reinforcing silica. SILASTIC BioMedical Grade ETR Elastomers, when fully cured and washed, meet the requirements of FDA regulation 21CFR117.2600. Some typical properties are shown in Table 1, below. ${ }^{11}$ 


\begin{tabular}{|c|c|c|c|c|c|c|c|}
\hline \multicolumn{8}{|c|}{$\begin{array}{l}\text { Table 2: TYPICAL PROPERTIES } \\
\text { Specification Writers: Please contact your local Dow Corning sales office or your global Dow Corning connection before writing } \\
\text { specifications on these products. (continued) }\end{array}$} \\
\hline \multirow[b]{2}{*}{$C T M^{\prime}$} & \multirow[b]{2}{*}{ Test } & \multirow[b]{2}{*}{ Unit } & \multicolumn{5}{|c|}{ SILASTIC BioMedical Grade ETR Elastomers } \\
\hline & & & $07-4720$ & $07-4735$ & $07-4750$ & $07-4765$ & $07-4780$ \\
\hline \multicolumn{8}{|c|}{ Post-cured - 2 hours at $177^{\circ} \mathrm{C}\left(350^{\circ} \mathrm{F}\right)$} \\
\hline 0099 & Durometer hardness, Shore A & & 46 & 44 & 57 & 75 & 83 \\
\hline \multirow[t]{2}{*}{ 0137A } & Tensile strength & $\mathrm{MPa}$ & 9.78 & 8.35 & 9.96 & 7.48 & 6.96 \\
\hline & & psi & 1419 & 1210 & 1444 & 1085 & 1010 \\
\hline 0137A & Elongation & $\%$ & 767 & 833 & 647 & 649 & 483 \\
\hline \multirow[t]{2}{*}{ 0137A } & Modulus, $200 \%$ & $\mathrm{MPa}$ & 1.53 & 1.99 & 3.03 & 3.7 & 4.12 \\
\hline & & psi & 222 & 289 & 440 & 536 & 597 \\
\hline \multirow[t]{2}{*}{$0159 \mathrm{~A}$} & Tear strength, Die B & $\mathrm{kN} / \mathrm{m}$ & 30.6 & 34.5 & 46.4 & 39.4 & 26.3 \\
\hline & & ppi & 175 & 197 & 265 & 225 & 150 \\
\hline 1057 & Shrinkage & $\%$ & $\mathrm{~N} / \mathrm{A}$ & 2.3 & 2.4 & 2.3 & 2.3 \\
\hline 0085 & Compression set, 22 hours at $177^{\circ} \mathrm{C}\left(350^{\circ} \mathrm{F}\right)$ & $\%$ & 33.6 & 34.9 & 45.8 & 76.2 & 81.2 \\
\hline
\end{tabular}

\subsubsection{Polyurethane}

Many formulations of polyurethane (PU) elastomers were introduced as lead insulation material in 1978. This material was advantageous because of its high tensile strength and flexibility, low coefficient of friction, good biocompatibility, and low thrombogenicity. Because of their superior mechanical properties, polyurethanes allow for thinner lead design compared to silicone leads. Many manufactures went towards polyurethane in the early 1980's, but half of a decade later it was proven that PU leads suffered from considerable in vivo degradation.

The fundamental modes of failure are environmental stress cracking and metal ion oxidation (MIO). Multiple polyurethane elastomer blends have been used, starting with Pellethane 2363 80-A. Later Pellethane 2363 55D, which has fewer polyether segments, was introduced to utilize its stiffness and reduce stress cracking. Because the degradation of polyether urethanes is partly related to the presence of its ether segments, formulations eliminating linkages altogether appear desirable. However, ideal polyurethane formulations exhibiting both resistance to oxidation and hydrolysis remain to be developed. This study will attempt to characterize the chemical degradation of two different polyurethane elastomer blends (see section 1.2.5.). ${ }^{10,12}$ 


\subsubsection{Poly (styrene-isobutylene-styrene) (PIBS)}

The relatively new thermoplastic elastomer (TPE) Poly(styrene-isobutylene-styrene) (PIBS) is a tri-block copolymer consisting of a polyisobutylene inner segment connected to two polystyrene outer segments. These kinds of phase segregated polymers can exhibit unique chemical and physical properties that be used for many applications because the distinct phases can be tailored to meet desired mechanical and chemical properties. PIBS is a 3-phase copolymer that has a three block chain arranged in an S-B-S series (Figure 2). The major component of the PIBS copolymer is polyisobutylene, which accounts for $70-85 \%$ by weight of the base polymer. The polyisobutylene is the soft segment of the copolymer and gives the material flexibility as well as its low permeability. The polystyrene segment normally compromises $15-30 \%$ by weight and forms a hard, glassy region that provides its mechanical strength. In the solid state, the thermodynamic immiscibility of the two components results in a micro-phase separation where domains of polystyrene are formed in the rubber polyisobutylene matrix. ${ }^{13,15,16}$

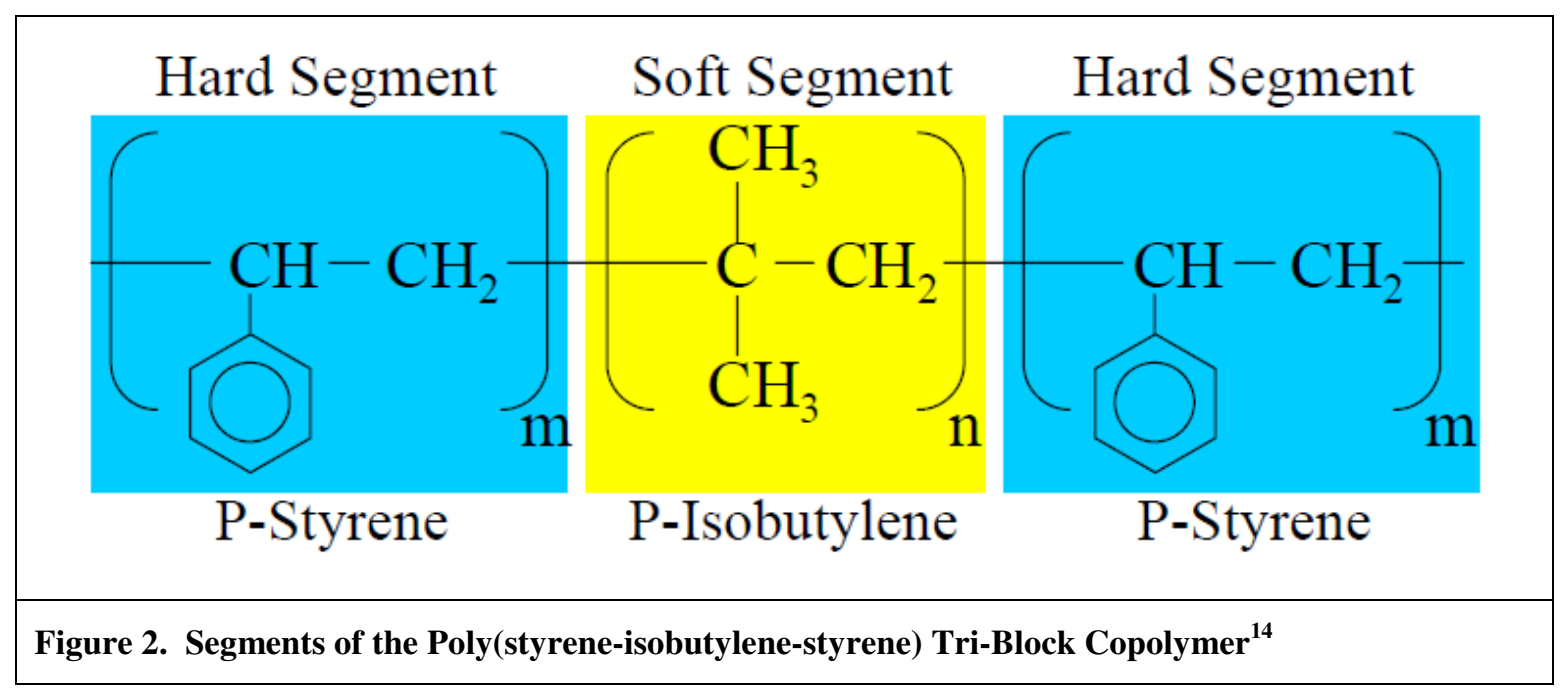

The emergence of living carbocationic polymerization provided the simplest and most convenient method for the preparation of block copolymers by sequential monomer addition. PIBS is created by this method, which is a chain polymerization process that proceeds in the 
absence of chain transfer to monomer and irreversible termination. The irreversibility or termination is emphasized, because in contrast to conventional living anionic polymerizations, in living cationic polymerizations the concentration of the cations is very small. ${ }^{17}$ The nature, activities, and concentration of the active species in cationic polymerization is determined by the mechanisms of initiation, which will determine the head and end groups. Organic esters, halides, ethers, and alcohols have been used to initiate living polymerization of isobutylene. The synthesis of PIBS involves sequential monomer addition using di- or trifunctional initiator in conjunction with $\mathrm{TiCl}_{4}$ in moderately polar solvent mixture at low temperatures. ${ }^{17}$

PIBS has good low and high temperature properties with a maximum service temperature of $65^{\circ} \mathrm{C}$ and a minimum service temperature of $-50^{\circ} \mathrm{C}$. It has good aging resistance, resistance to chemical agents, and good electrical insulating properties. Preliminary environmental tests indicated that polyisobutylene based materials exhibit improved hydrolytic stability and reduced moisture permeability compared to polyether and polyester polyurethanes. They also have been shown to exhibit greater oxidative stability compared to polybutadiene based materials, but because of the aromatic ring containing structure of polystyrene, PIBS may be oxidizable.

The PIBS elastomer used in this study is SIBSTAR® manufactured by Kaneka Corp. This material has the opportunity to be successful as a lead insulation material because of its abrasion resistance, flexibility, low gas permeability, and biostability. SIBSTAR® is available in a few different variations of molecular weight and wt $\%$ of styrene, but this study focuses on SIBSTAR® ${ }^{\circledR}$ 73T, which has a molecular weight of 65,000 and a styrene $30 \mathrm{wt} \%$ styrene content (Table 2). ${ }^{14}$ 


\begin{tabular}{|c|c|c|c|c|c|c|c|}
\hline \multicolumn{2}{|c|}{ Properties } & \multirow{2}{*}{$\begin{array}{l}\text { Method \& } \\
\text { Condition }\end{array}$} & \multirow{2}{*}{$\begin{array}{l}\text { Unit } \\
\mathrm{g} / \mathrm{cm}^{3}\end{array}$} & \multirow{2}{*}{$\begin{array}{c}\text { SIBSTAR } \\
\text { 073T } \\
0.954\end{array}$} & \multirow{2}{*}{$\begin{array}{c}\text { SIBSTAR } \\
\text { 072T } \\
0.946\end{array}$} & \multirow{2}{*}{$\begin{array}{c}\text { SIBSTAR } \\
\text { 103T } \\
0.954\end{array}$} & \multirow{2}{*}{$\begin{array}{c}\text { SIBSTAR } \\
\text { 102T } \\
0.942 \\
\end{array}$} \\
\hline Specific Gravity & Specific Gravity & & & & & & \\
\hline Flexibility & Hardness & $\begin{array}{l}\text { JIS K6253 } \\
\text { (15sec) }\end{array}$ & JIS-A & 45 & 33 & 46 & 25 \\
\hline \multirow{2}{*}{ Flow } & Melt Flow Rate & $\begin{array}{c}\text { JIS K7210 } \\
230^{\circ} \mathrm{C}, 2.16 \mathrm{kgf}\end{array}$ & $\mathrm{g} / 10 \mathrm{~min}$ & 7 & 6 & 0.1 & 0.6 \\
\hline & Apparent Viscosity & $\begin{array}{c}\text { JIS K7199 } \\
230^{\circ} \mathrm{C}, 1,220 \text { sec }^{1}\end{array}$ & Poise & 2,000 & 2,000 & 4,000 & 3,000 \\
\hline \multirow{3}{*}{$\begin{array}{l}\text { Tensile } \\
\text { Properties }\end{array}$} & Strength @Break & \multirow{3}{*}{$\begin{array}{c}\text { JIS K6251 } \\
\text { No,3 Dumbbe\|l } \\
23^{\circ} \mathrm{C}\end{array}$} & $\mathrm{MPa}$ & 14 & 13 & 18 & 15 \\
\hline & Elongation @Break & & $\%$ & 650 & 670 & 620 & 870 \\
\hline & Modulus @100\% & & $\mathrm{MPa}$ & 0.9 & 0.7 & 1.0 & 0.5 \\
\hline Permanent Set & Compression Set & $\begin{array}{c}\text { JIS K6262 } \\
70^{\circ} \mathrm{C}, 22 \mathrm{hrs}\end{array}$ & $\%$ & 70 & - & 50 & 65 \\
\hline
\end{tabular}

\subsubsection{PIBS Blends - Polypropylene (PP)}

Polypropylene provides excellent resistance to organic solvents and electrolytic attack. It has a relatively low impact strength, but adequate operational temperatures and tensile strength. It is also light in weight and has a low moisture absorption rate. It has excellent resistance to acids and alkalines, but poor resistance to aromatic, aliphatic and chlorinated solvents. When blended with PIBS, Poly(isobutylene-propylene) can utilize the superior mechanical and chemical properties of both blocks of the copolymer.

\subsubsection{PIBS Blends - Polyurethane (PU)}

Polyisobutylene based polyurethanes belong to the class of elastomeric PUs. The reason for interest in PIB based PUs is to make up for certain material deficiencies in pure polyurethanes. Major weaknesses of conventional polyester and polyether based PUs are low acid, base, hydrolytic, steam, and environmental stability and a maximum service temperature of 
only about $105^{\circ} \mathrm{C}$. It is anticipated that PUs prepared from hydroxyl terminated PIBS will alleviate these deficiencies. ${ }^{19}$

\subsubsection{Silicone Adhesive}

In cardiac rhythm management devices, silicone (polysiloxane) adhesives are frequently used as sealants around the connection of a lead to the pulse generator. Silicone adhesives cure without the application of heat or pressure to form permanently flexible silicone rubber. They usually come in one-part or two-part systems; one-part systems being the least expensive, no mixing, ready to use, and two-part systems requiring no moisture to cure.

Adhesion relies on mainly mechanical and chemical mechanisms to form a bond between two materials. The cure system consists of hydroxyl-terminated polymers, alkyltriacetoxysilane cross-linkers, and a catalyst that begin cross-linking by condensation once the system comes in contact with moisture, usually from humidity in the ambient air. A byproduct of the condensation reaction is acetic acid, which cannot be controlled through process additives or substitutes, but does not typically cause any negative affects. Complete cure time depends on silicone thickness and relative humidity. The high elastomeric property of silicone adhesives gives them the ability to absorb movement. This allows silicone adhesives to be used in applications where the adhesive is required to absorb movements of the joint without tearing apart from the substrate..$^{20,4,21}$

The silicone adhesive used in this study is Med-2000, which is manufactured by Nusil Technology in Carpinteria, CA. According to the product profile from Nusil, Med-2000 improves the adhesion of addition-cured systems and two-component silicone rubbers to various substrates including: metals (such as stainless steel, steel, copper, and aluminum), ceramics, rigid plastics, and other silicone materials. ${ }^{22}$ Med-2000 has not been previously defined for use with PIBS or any PIBS blends. The manufacturer states that curing or vulcanization time depends 
upon the thickness of the silicone adhesive layer, relative humidity, and accessibility of atmospheric moisture to the curing adhesive. For sections of typical thickness, a relative humidity level between $20-60 \%$ is recommended to cure the adhesive at room temperature. Generally the adhesive forms a thick, tack-free outer skin for thick section films within a few minutes after application. The vulcanization rate slows when exposing very thin films to excessive humidity ( $\geq 80 \%$ relative humidity). For films below 80 microns, the relative air humidity should be within 30-50\%. Table 3 shows some typical properties of Med-2000.

Table 3 - Typical Properties of the Nusil Med-2000 Silicone Adhesive ${ }^{22}$

\begin{tabular}{|c|c|c|c|c|c|c|}
\hline \multirow{2}{*}{ Typical Properties } & \multicolumn{2}{|c|}{ Result } & \multicolumn{2}{|c|}{ Metric Conv. } & \multirow{2}{*}{ ASTM } & \multirow{2}{*}{ NT-TM } \\
\hline & MED-2000 & MED-1511 & MED-2000 & MED-1511 & & \\
\hline \multicolumn{7}{|l|}{ Uncured: } \\
\hline Appearance & \multicolumn{2}{|c|}{ Translucent } & \multicolumn{2}{|c|}{-} & D2090 & 002 \\
\hline Volatility & $2.3 \%$ & $2.5 \%$ & - & - & D2288 & 004 \\
\hline Flow Rate* & 2 inches & 2 inches & $50.8 \mathrm{~mm}$ & $50.8 \mathrm{~mm}$ & D2202 & 019 \\
\hline Tack-Free Time & $10 \mathrm{~min}$. & $10 \mathrm{~min}$. & - & - & C679 & 005 \\
\hline \multicolumn{7}{|l|}{ 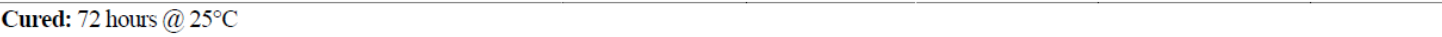 } \\
\hline Specific Gravity & 1.08 & 1.12 & - & - & D792 & 003 \\
\hline Durometer, Type A & 25 & 25 & - & - & D2240 & 006 \\
\hline Tensile Strength & $1,175 \mathrm{psi}$ & $1,400 \mathrm{psi}$ & $8.1 \mathrm{MPa}$ & $9.7 \mathrm{MPa}$ & D412, D882 & 007 \\
\hline Elongation & $700 \%$ & $800 \%$ & - & - & D412, D882 & 007 \\
\hline Tear Strength, Die B & $90 \mathrm{ppi}$ & $100 \mathrm{ppi}$ & $15.8 \mathrm{kN} / \mathrm{m}$ & $17.6 \mathrm{kN} / \mathrm{m}$ & D624 & 009 \\
\hline Stress@200\% Strain & $110 \mathrm{psi}$ & $105 \mathrm{psi}$ & $0.76 \mathrm{MPa}$ & $0.72 \mathrm{MPa}$ & D412, D882 & 007 \\
\hline
\end{tabular}

\subsubsection{Primer}

Silane primers chemically functionalize the bonding surface to provide pathways for chemical bonding with a selected silicone cure system, which promote adhesion between two non-bonding surfaces (Figure 3). The primers usually consist of one or more reactive silanes, a condensation catalyst, and a solvent carrier. The silanes usually have two different reactive groups such as a hydrophilic silanol (Si-OH) or a hydrophobic 1-octenyl group. These groups form the two different surfaces the ability to bond with one another. The silanes and the condensation catalyst, upon exposure to ambient humidity, form a thin polymeric film on the bonding surface. The catalyst promotes cross-linking of the adhesive and bonding to the primer 
film layers. It is important to avoid an overly primed surface that form a chalky film and can be a point of bond failure. $^{23}$

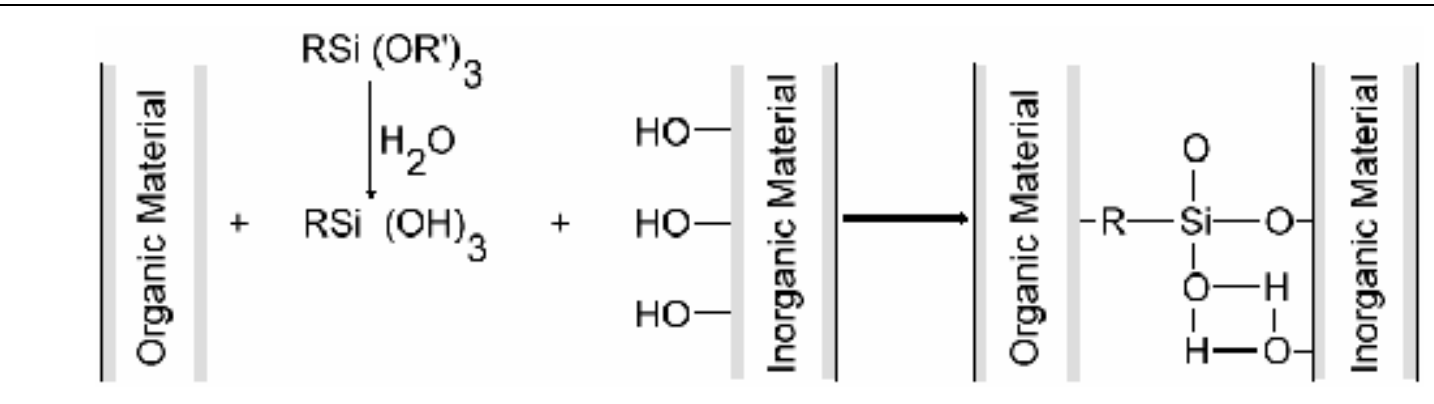

Figure 3. Silane Primer Adhesion Promotion

The primer used in this study is SP-135 High Technology Silicone Primer (Clear) and is also manufactured by Nusil Technology. SP-135 is a specially formulated, clear primer, designed for use with platinum-cured silicone systems. According to the Nusil product profile, it improves the adhesion of addition-cured systems and two-component silicone rubbers to various substrates including: metals (such as stainless steel, steel, copper and aluminum), ceramics, rigid plastics, and other silicone materials. Typical properties of Nusil SP-135 Silane Primer are shown in Table $4 .^{24}$

Table 4 - Typical Properties of the Nusil SP-135 Silane Primer ${ }^{24}$

\begin{tabular}{lcccc}
\hline Typical Properties & Result & Metric Conv. & ASTM & NT-TM \\
\hline Color & Clear to slightly cloudy & - & - & - \\
Viscosity & $1.0 \mathrm{cP}$ & - & D-1084, D-2196 & 001 \\
Non-Volatile Content & $4.5 \%$ & - & D-2288 & 004 \\
Specific Gravity @ $25^{\circ} \mathrm{C}\left(77^{\circ} \mathrm{F}\right)$ & 0.76 & - & D-792 & 003 \\
Flash Point, (TCC) & $50^{\circ} \mathrm{F}$ & $10^{\circ} \mathrm{C}$ & $\mathrm{D}-92$ & 092 \\
Solvent Type & VM\&P Naphtha & - & - & - \\
D.O.T. Classification & Flammable Liquid & & - & - \\
\hline
\end{tabular}




\subsection{Degradation of Polymers}

Degradation characteristics of polymers are important to discuss because a large portion of this study serves to characterize the degradation of selected PIBS based polymers in comparison to a commonly used control (silicone). Polymers that are biologically degradable contain functional groups that promote enzymatic hydrolysis and oxidation.

\subsubsection{Environment of the Human Body}

By definition, biodegradation is the chemical breakdown of materials by the action of living organisms that lead to change in physical properties. On the surface it seems that the neutral $\mathrm{pH}$ level, mild temperature, and low salt content of the body would provide a noncorrosive environment, but in reality there are many unique mechanisms that act on an implantable medical device. Post-implantation, both absorption and adsorption occur when cellular components in the body's organic fluid attach to the surface and diffuse into the bulk of a material. These cellular components initiate the chemical processes that lead to biodegradation. ${ }^{4}$

\subsubsection{Hydrolysis}

Hydrolysis is defined as the scission of vulnerable functional groups by reaction with water, which may be catalyzed by acids, bases, salts, or enzymes. ${ }^{4}$ The most susceptible functional groups include esters, amides, and carbonates. Because hydrolysis results in chain cleavage, the physical properties of the material can be affected through a negative change in molecular weight. Ion-catalyzed hydrolysis is the most likely cause of degradation in medical implants using hydrolysable polymers. Bodily fluids contain the common ions $\mathrm{H}^{+}, \mathrm{OH}^{-}, \mathrm{Na}^{+}, \mathrm{Cl}^{-}$, $\mathrm{HCO}_{3}{ }^{-}, \mathrm{K}^{+}, \mathrm{Mg}^{2+}$, and $\mathrm{Ca}^{2+}$, which are all effective hydrolysis catalysts. In addition to the hydrolytic catalysts, localized $\mathrm{pH}$ changes in the vicinity of an implanted device due to 
inflammation or infection can cause an increase in the rate of hydrolysis. ${ }^{4}$ The PIBS structure is composed of alkyl blocks, which are highly resistant to hydrolytic degradation.

\subsubsection{Oxidation}

There are several different modes of oxidation, which include autooxidation, oxidation by peroxides, free radicals, enzymes, and metal-ion oxidation. The functional groups most susceptible to oxidation include ethers, aromatics, phenols, alcohols, amines, and aldehydes. Failure of polymers used for pacemaker lead insulation typically occurs from two mechanisms: environmental stress cracking (ESC) and metal ion oxidation (MIO). ESC occurs from direct contact with human tissue and MIO from direct contact with the lead conductor coils.

Environmental stress cracking is characterized by deep, ragged fractures within the material, most often perpendicular to the applied stress. The MIO mechanism involves interaction between the metal of the conductor coil and hydrogen peroxide. In the case of pacemaker leads, hydrogen peroxide, a known product of inflammatory cells involved in the foreign body response.

Oxidation of a polymer usually leads to increased brittleness, reduced strength, and a yellowing in color. $^{25}$ 


\section{PURPOSE AND EXECUTION OF STUDY}

In order to take advantage of the properties of PIBS and PIB based blends as lead insulation materials, they must be able to sufficiently bond to the various materials that make up the cardiac device. The bonded PIBS must be able to withstand the mechanical stress and corrosive environment of the human body due to the long term use of these devices. Although silicone, one of the commonly used lead insulation materials, provides excellent resistance to biodegradation, it also possesses multiple drawbacks due to its relative softness. First, its softness can cause it to be prone to damage from abrasion upon implantation. Because of its relatively low tear strength, silicone lead insulation poses a major design restraint in moving toward the trend of smaller diameter pacing leads. The final disadvantage of silicone is its high coefficient of friction, which can lead to thrombosis. ${ }^{28}$

Based on the component requirements of lead insulation, the first objective of this study is to perform an initial screening of multiple poly(styrene-isobutylene-styrene) / stainless steel / silicone adhesive combinations. Based on the bonding shear strength results of the initial screening, the best performing combinations will be artificially aged to simulate their resistance to degradation in vivo. The combination that exhibits the best resistance to biodegradation can be considered the most ideal candidate for use as a lead insulation material.

\subsection{Phase I: Initial Screening}

\subsubsection{Objective and Deliverables}

The Phase I objective is to get initial silicone bond shear strength data for multiple PIBS blends compared to a control (silicone tubing). Based on the collected data, samples will be selected for further investigation in Phase II of this study. 
Phase I deliverables include:

- Raw data for silicone bond shear strength for PIBS blends to stainless steel and Silicone (control) to stainless steel.

- Statistical analysis of data to significance in difference between bond shear strengths of all combinations.

- Combinations selected for Phase II

\subsubsection{Materials and Equipment}

Below is a list of all materials and equipment required for Phase I of this study:

\section{$\underline{\text { Materials }}$}

- Adhesive: Nusil MED-2000 Silicone

- Primer: Nusil SP-135 Silane Primer

- PIBS Blends:

- $\quad$ SILASTIC Q7-4780 Silicone tubing

- $\quad$ SIBSTAR Poly(styrene-isobutylene-styrene) tubing (PIBS)

- $\quad$ PIBS / 10\%PP

- $\quad$ PIBS / 10\%55D Polyurethane

- $\quad$ PIBS / 10\%75D Polyurethane

- Bonding Substrate: EFD Stainless Steel Precision Tips 5118-B

Equipment

- Tensile Tester: Chatillon

- Load Cell: $11 \mathrm{lb}$

- Small Tip Camel Hair Brush

\subsubsection{Procedure and Methodology}

The following is the standard procedure used to produce and test samples including a justification of the method in italics where appropriate: 


\section{General Setup}

1.1. Clean surface and remove any unnecessary materials and equipment.

\section{Cut and Label Samples}

2.1. Using a clean razor blade, cut six, three inch long pieces of tubing for each sample group.

NOTE: Ensure that the cuts are made straight so that the tubing face is perpendicular to ground.

Cuts must be straight to keep the bonding surface area consistent between samples.

2.2. Label trays with each sample group name and store samples in the appropriate tray.

\section{Apply Primer}

3.1. Using a small tip camel hair brush, apply a thin layer of primer to the inside diameter of each tube of the six tubes in one group approximately $4 \mathrm{~mm}$ deep.

NOTE: If primer dries to a whitish or chalky appearance, the coating is too thick. Discard and replace the tube and reapply primer with a thinner layer.

A small tipped brush was used to apply the primer due to its relatively low viscosity.

3.2. Record the time and date of primer application.

3.3. Repeat for each sample group.

3.4. Allow primer to dry for 1 hour at room temperature before proceeding to step 4.

Nusil's product profile suggests a dry time of 30 minutes at room temperature, but to ensure a complete curing, a dry time of 1 hour at room temperature was used for this study.

\section{Apply Silicone Adhesive}

4.1. Using Figure 4 as a reference to replicate the amount of adhesive, insert the tip of an EFD Stainless Steel Tip into the MED-2000 Silicone Adhesive so that a small amount of adhesive remains on the tip after removal.

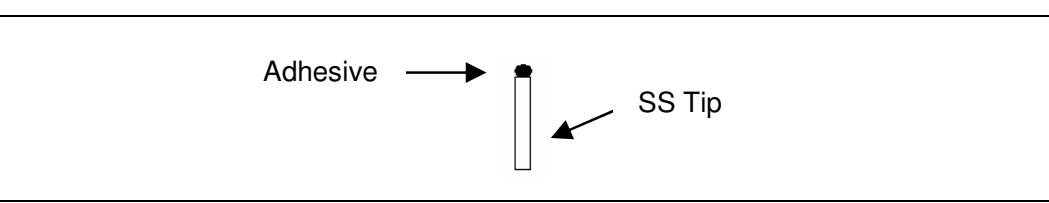

Figure 4. Adhesive quantity reference.

This method is considered to have a large potential to produce variance in the output. An ideal method, perhaps using a time and pressure controlled dispensing system, would precisely control the amount of adhesive used for bonding.

4.2. With a target depth of $2 \mathrm{~mm}$, insert the stainless steel tip into the polymer tubing.

NOTE: Do not retract the SS tip after reaching the desired insertion depth. 
4.3. Gently wipe any excess adhesive on the SS tip above the tubing with a lintfree cloth.

To truly observe the bond shear strength between the needle and tubing it was important to ensure that the adhesive did not extend outside of the ideal bonding area (i.e. adhesive beyond the needle inside of the tube, or above the tube on the needle surface). This method minimized variation in bond shear strength due to adhesive application. Due to the difficulty of consistently inserting the needle to a depth of $2 \mathrm{~mm}$, the actual insertion depth was measured prior to pull testing.

4.4. Twist the needle clockwise, then counter-clockwise $180^{\circ}$ in each direction to ensure adhesive covers the entire bonding surface.

4.5. Record time and date of bonding.

4.6. Repeat for all samples in each sample group.

There were 6 replicates for 5 sample groups for a total of 30 samples.

4.7. Allow adhesive to cure for 72 hours before continuing to step 5 .

\section{Tensile Test}

5.1. Measure the bond length of each sample using a pair of calipers.

5.2. Using the cutting surface of a pair of pliers, clip the plastic connector from each SS tip.

NOTE: Use care to not disrupt the bond during removal of connector.

5.3. Place the SS tip into the lower clamp and the tubing end into the upper

5.4. Using a gauge length of 2 " and a pull speed of $1 \mathrm{~mm} / \mathrm{sec}$, perform a tensile test one the samples from each sample group (Figure 5).

NOTE: Ensure that the sample is aligned vertically between the upper and lower clamps.

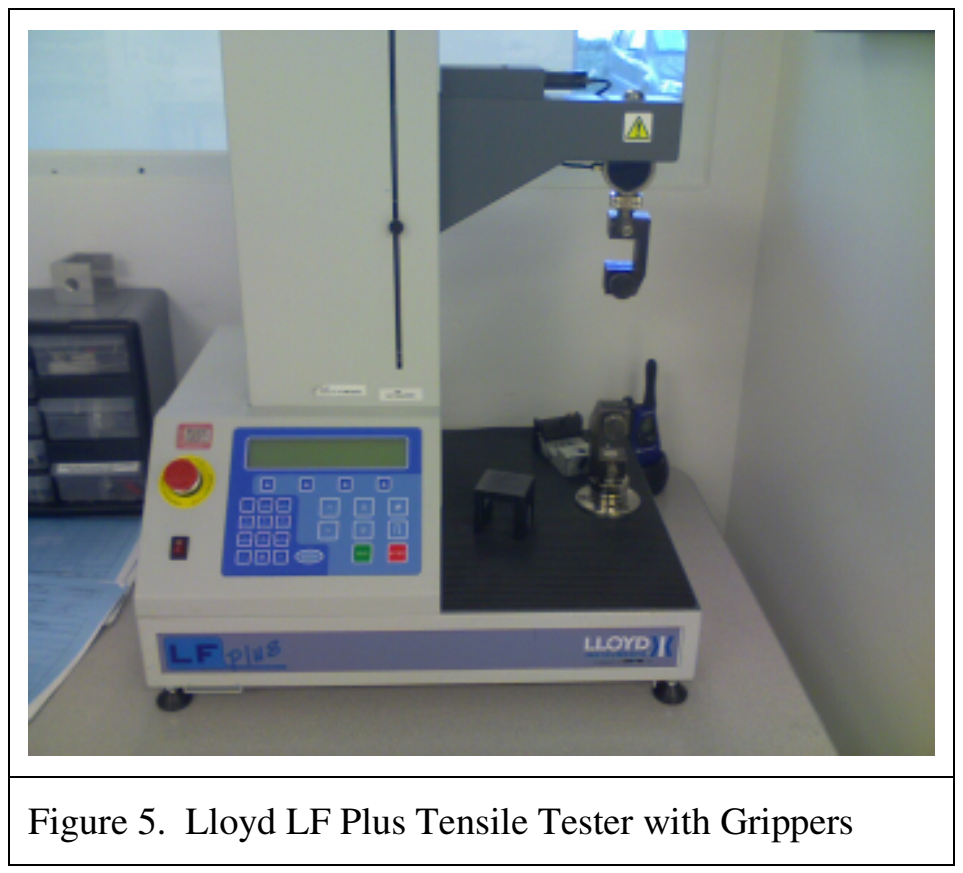


5.5. Record tensile strength for each sample and whether the sample failed at the tube or at the bond.

\section{Calculate Bonding Shear Strength}

6.1. Use Hooke's Law (1) to calculate the shear strength $(\tau)$, where:

$$
\begin{aligned}
& \tau=\frac{P}{A} \\
& \mathrm{P}=\text { Maximum Load } \\
& \mathrm{A}=\text { Bond Area }
\end{aligned}
$$

The bond area was calculated using the measured SS tip insertion depth (d) and outer diameter $(1.26 \mathrm{~mm}): A=2 \pi r \times d$. Bond shear strength is the critical output of Phase I.

\section{Statistical Analysis}

7.1. Calculate descriptive statistics (mean, standard deviation, min, max, etc).

7.2. Perform two-sample t-tests with a $95 \%$ confidence level for each sample group against all others to determine if there is a significant difference between them.

\subsection{Phase II: Aging Stability}

\subsubsection{Objectives and Deliverables}

For a lead insulation to be effective, it must withstand the harsh environment of the human body for an extended period of time. Phase II of this study served to simulate the hydrolytic and oxidative instability of the PIBS blends through artificial aging. Because of the interest in observing the aging characteristics of all sample groups, the decision was made to use all materials for the second phase of this study.

\subsubsection{Materials and Equipment}

The following is a list of materials and equipment used during Phase II of this study:

$\underline{\text { Materials }}$

- Adhesive: Nusil MED-2000 Silicone

- Primer: Nusil SP-135 Silane Primer

- PIBS Blends:

- $\quad$ SILASTIC Q7-4780 Silicone tubing

- $\quad$ SIBSTAR Poly(styrene-isobutylene-styrene) tubing (PIBS) 
- $\quad$ PIBS / 10\%PP

- $\quad$ PIBS / 10\%55D Polyurethane

- PIBS / 10\%75D Polyurethane

- Bonding Substrate: EFD Stainless Steel Precision Tips 5118-B

- Treatment Media:

- Fisher Scientific 3\% USP Hydrogen Peroxide $\left(\mathrm{H}_{2} \mathrm{O}_{2}\right)$

- Fisher Scientific Phosphate Buffered Saline (PBS) (BP661-10)

- Distilled $\mathrm{H}_{2} \mathrm{O}$

Equipment

- Tensile Tester: Chatillon

- Load Cell: $11 \mathrm{lb}$

- Small Tip Camel Hair Brush

- Lab Oven: LabLine L-C Oven

- Test Tubes

\subsubsection{Procedure and Methodology}

The following is the standard procedure used to produce, artificially age, and test samples including a justification of the method in italics where appropriate:

\section{Sample and Solution Preparation}

1.1. Prepare samples using identical methods from Sections 1-4 from Phase I.

6 replicates were produced for each material / solution / time interval for a total of 240 samples.

1.2. Prepare and label test tubes for each material / solution / time interval combination (e.g. PIBS / $\mathrm{H}_{2} \mathrm{O}_{2} / 2$ Weeks) (Figure 6). 


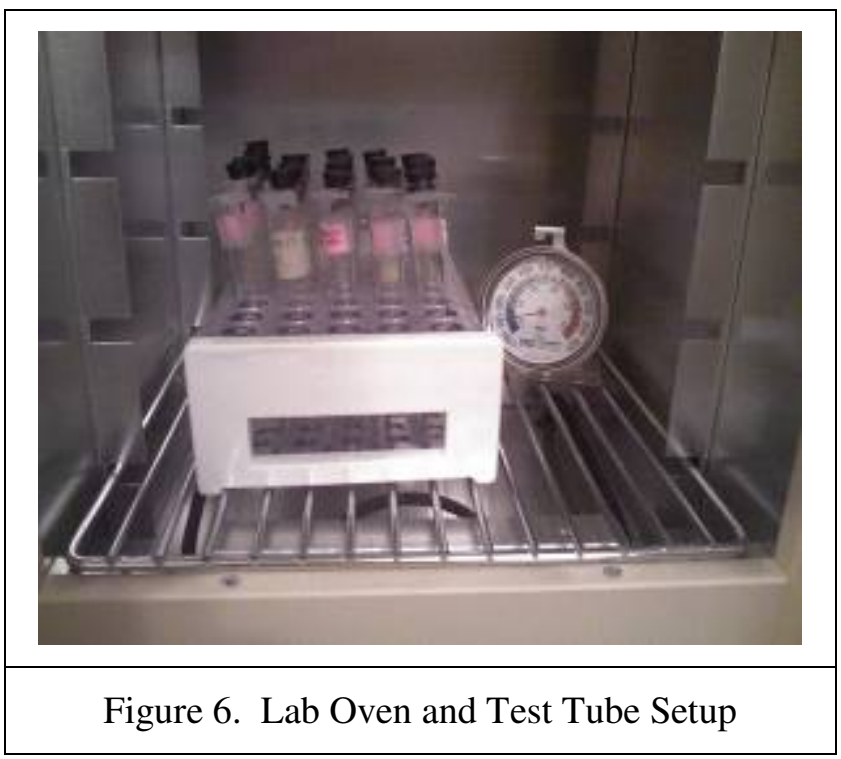

1.3. Fill the appropriate test tubes about $3 / 4$ full with the Fisher Scientific $\mathrm{H}_{2} \mathrm{O}_{2}$.

1.4. Mix approximately $10 \mathrm{~g}$ of $\mathrm{PBS}$ powder with $1000 \mathrm{~mL}$ of distilled $\mathrm{H}_{2} \mathrm{O}$ and fill the appropriate test tubes about $3 / 4$ with the PBS solution.

The PBS solution was formulated to match the osmolarity and ion concentrations of the human body.

1.5. Submerge the samples in their respective test tubes.

NOTE: Ensure that all samples are completely immersed in solution.

1.6. Place the rubber stoppers into the test tubes, slightly venting the $\mathrm{H}_{2} \mathrm{O}_{2}$ tubes and securely closing the PBS tubes.

$\mathrm{H}_{2} \mathrm{O}_{2}$ tubes were slightly vented to allow for the oxygen byproduct to escape.

1.7. Place all test tubes inside the lab oven at $70^{\circ} \mathrm{C}$

\section{Sample Removal and Testing}

2.1. Remove respective samples for each solution at 2 week intervals.

2.2. Rinse removed samples with distilled water and allow to air dry for a minimum of 72 hours.

2.3. Perform a tensile test on each sample in the same manner as Section 5 from Phase I.

2.4. Calculate the bonding shear strength as done in Section 6 from Phase I.

\section{Statistical Analysis}

3.1. Calculate descriptive statistics for each sample group (mean, standard deviation, min, max, etc).

3.2. Perform two-sample t-tests with a $95 \%$ confidence level for each sample group at its original value (un-aged) vs. the 8 -week value. 


\section{RESULTS}

\section{1. $\quad$ Phase I Results}

\subsubsection{Statistical Summary}

Table 5 shows the mean, standard deviation, min, median, maximum, and range for each sample group of six units plus the silicone control (all values are given in megapascals).

\begin{tabular}{|c|c|c|c|c|c|c|c|}
\hline \multicolumn{8}{|c|}{ PIBS/SS: SP-135 + Med2000 } \\
\hline Variable & Count & Mean & StDev & Minimum & Median & Maximum & Range \\
\hline $\mathrm{PIBS} / \mathrm{SS}$ & 6 & 0.4065 & 0.0483 & 0.3460 & 0.4050 & 0.4870 & 0.1410 \\
\hline \multicolumn{8}{|c|}{ 10\%PP/SS: SP-135 + Med2000 } \\
\hline Variable & Count & Mean & StDev & Minimum & Median & Maximum & Range \\
\hline $10 \% \mathrm{PP} / \mathrm{SS}:$ & 6 & 0.4313 & 0.0897 & 0.3530 & 0.4050 & 0.5960 & 0.2430 \\
\hline \multicolumn{8}{|c|}{ 10\%55D/SS: SP-135 +Med2000 } \\
\hline & Total & & & & & & \\
\hline Variable & Count & Mean & StDev & Minimum & Median & Maximum & Range \\
\hline $10 \div 55 \mathrm{D} / \mathrm{SS}:$ & 6 & 0.5602 & 0.0356 & 0.5060 & 0.5630 & 0.6010 & 0.0950 \\
\hline \multicolumn{8}{|c|}{ 10\%75D/SS: SP-135 + Med2000 } \\
\hline & Total & & & & & & \\
\hline Variable & Count & Mean & StDev & Minimum & Median & Maximum & Range \\
\hline $10 \div 75 \mathrm{D} / \mathrm{SS}:$ & 6 & 0.5133 & 0.0662 & 0.4320 & 0.5170 & 0.5930 & 0.1610 \\
\hline \multicolumn{8}{|c|}{ Silicone/SS: Med2000 (CONTROL) } \\
\hline & Total & & & & & & \\
\hline Variable & Count & Mean & StDev & Minimum & Median & Maximum & Range \\
\hline Silicone/SS: & 6 & 0.7853 & 0.1105 & 0.6300 & 0.7715 & 0.9700 & 0.3400 \\
\hline
\end{tabular}

For initial silicone bonding strength, the $10 \% 55 \mathrm{D}$ sample group had the highest mean bonding shear strength at $0.560 \mathrm{MPa}$ while PIBS had the lowest value of $0.407 \mathrm{MPa}$. Figure 7 summarizes the Phase I data with boxplots of the four sample groups and the control group. 
Bonding shear strength values for all sample groups were considerably lower than that of the silicone control group.

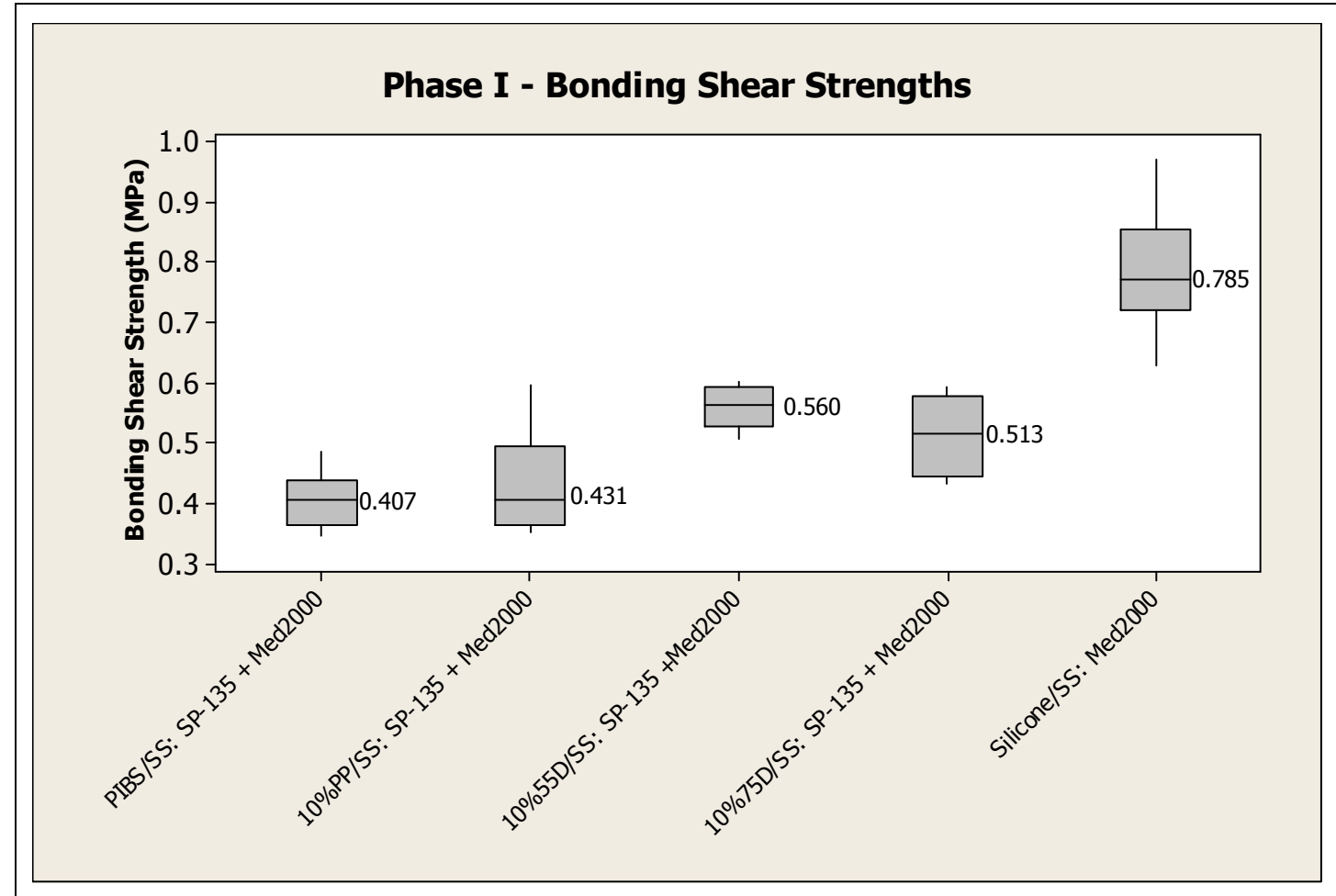

Figure 7. Phase I Initial Bonding Shear Strength Box Plots

\subsubsection{Statistical Analysis}

The Phase I results were analyzed using two sample t-tests to determine whether the difference in the data between the sample groups was statistically significant. All groups were tested against each other for significance (Table 6). The hypothesis test is stated by the following:

$\mathrm{H}_{0}$ : There is no difference between the mean bonding shear strength of the two sample groups

$\mathrm{H}_{1}$ : There is a difference between the mean bonding shear strength of the two sample groups 
A p-value less than 0.050 indicates that there is a significant difference between the two sample groups with $95 \%$ confidence, so the null hypothesis should be rejected. A p-value greater than 0.050 signifies no significant difference between sample groups and the null hypothesis would not be rejected.

Prior to executing the t-tests, normality of the data for each sample group was confirmed using the Anderson-Darling test for normality (Figure 8). All data was found to be normal.

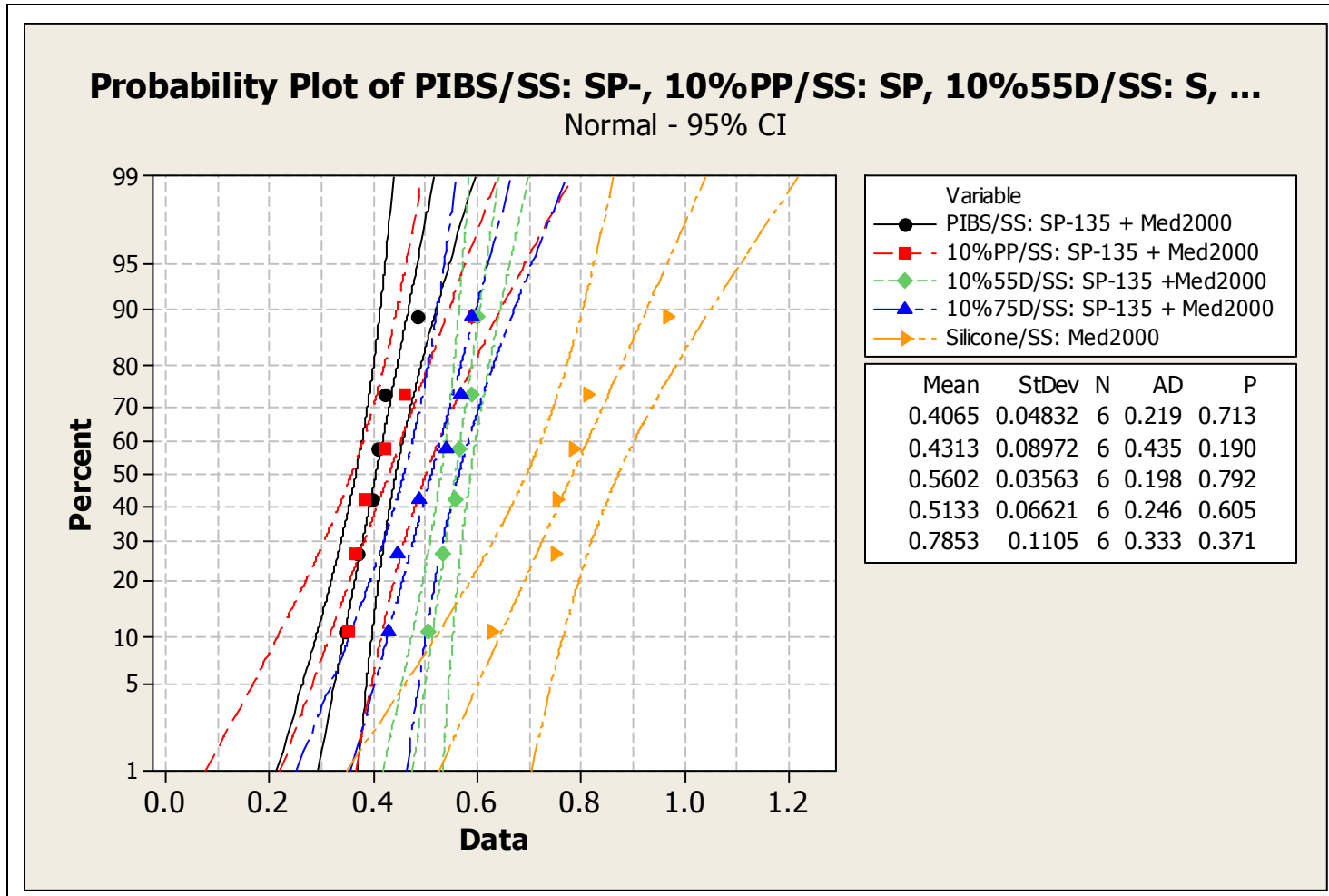

Figure 8. Phase I Probability Plot for Each Sample Group Showing Normality

A test for equal variances was also performed between each sample group. All variances were assumed equal with 95\% confidence except for 10\%55D vs. Silicone (control) (Figure 9). 


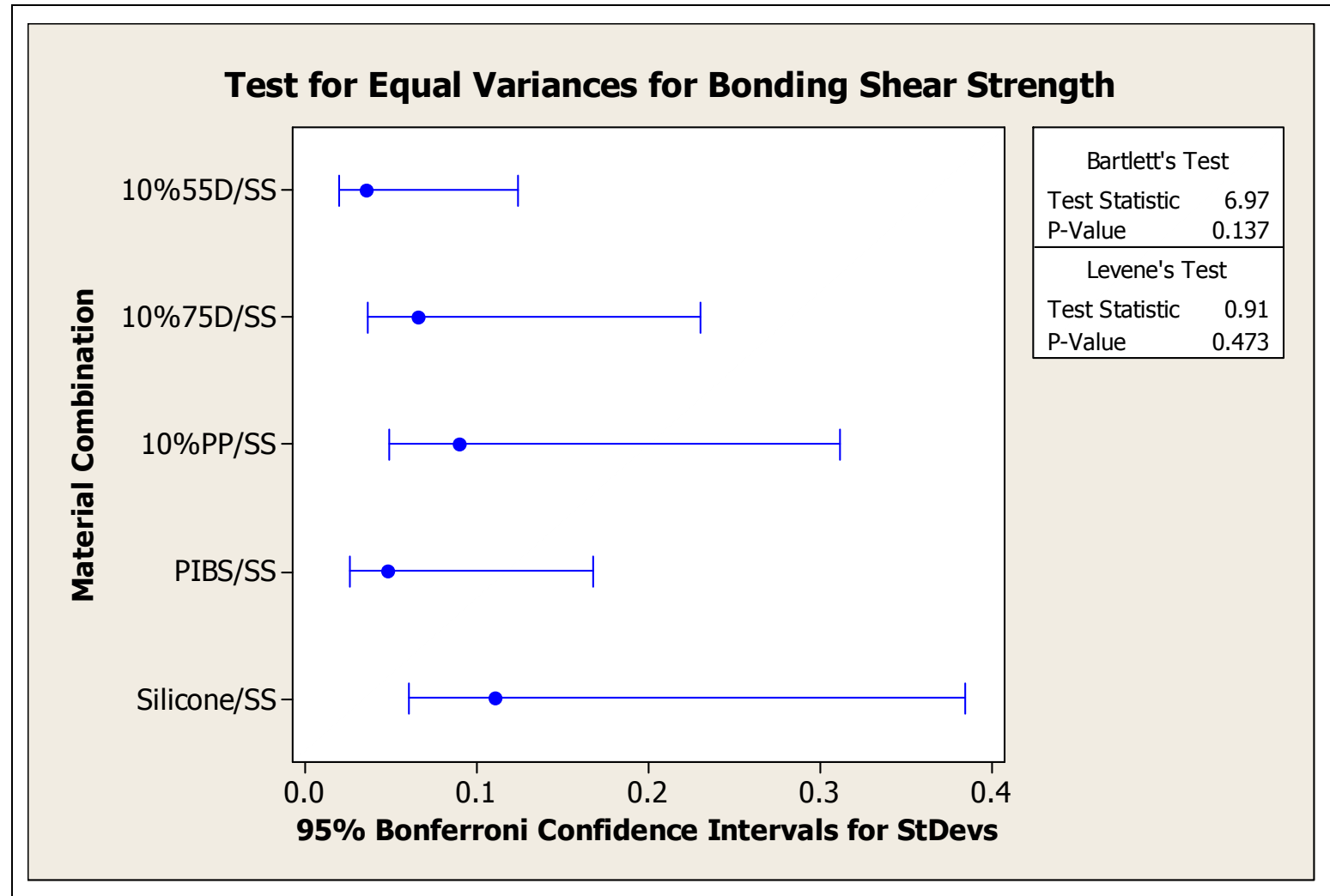

Figure 9. Phase I Test for Equal Variances

Note: all tests not shown

T-tests showed significant difference in initial bonding shear strength for the following sample groups: PIBS vs. $10 \% 55 \mathrm{D}$, PIBS vs. $10 \% 75 \mathrm{D}$, PIBS vs. Silicone control, $10 \%$ PP vs. $10 \% 55 \mathrm{D}, 10 \% \mathrm{PP}$ vs. Silicone control, $10 \% 55 \mathrm{D}$ vs. Silicone control, and 10\%75D vs. Silicone control. The null hypothesis was rejected for the previously mentioned sample group comparisons. For PIBS vs. $10 \%$ PP, $10 \%$ PP vs. $10 \% 75 \mathrm{D}$, and $10 \% 55 \mathrm{D}$ vs. $10 \% 75 \mathrm{D}$ the data showed no significant difference and the null hypothesis was not rejected. The $10 \% 55 \mathrm{D}$ sample group showed the best initial bonding shear strength, but due to the interest in aging characteristics of each groups, it was determined to use all four plus the silicone control for Phase II. 
Table 6 - Two Sample T-Test for Significant Difference Between Phase I Mean Bonding Shear Strengths for Each Group

\begin{tabular}{|c|c|c|c|c|c|c|c|c|c|c|}
\hline & \multicolumn{2}{|c|}{ PIBS/SS } & \multicolumn{2}{|c|}{$10 \% \mathrm{PP} / \mathrm{SS}$} & \multicolumn{2}{|c|}{$10 \% 55 \mathrm{D} / \mathrm{SS}$} & \multicolumn{2}{|c|}{$10 \% 75 \mathrm{D} / \mathrm{SS}$} & \multicolumn{2}{|c|}{ Silicone/SS } \\
\hline & $\begin{array}{c}\text { Equal } \\
\text { Variances? }\end{array}$ & $\begin{array}{l}\text { Significant } \\
\text { Difference? }\end{array}$ & $\begin{array}{c}\text { Equal } \\
\text { Variances? }\end{array}$ & $\begin{array}{c}\text { Significant } \\
\text { Difference? }\end{array}$ & $\begin{array}{c}\text { Equal } \\
\text { Variances? }\end{array}$ & $\begin{array}{l}\text { Significant } \\
\text { Difference? }\end{array}$ & $\begin{array}{c}\text { Equal } \\
\text { Variances? }\end{array}$ & $\begin{array}{c}\text { Significant } \\
\text { Difference? }\end{array}$ & $\begin{array}{c}\text { Equal } \\
\text { Variances? }\end{array}$ & $\begin{array}{l}\text { Significant } \\
\text { Difference? }\end{array}$ \\
\hline PIBS/SS & & & YES & $\begin{array}{l}\quad \text { NO } \\
\text { P-value = } \\
0.564\end{array}$ & YES & $\begin{array}{l}\quad \text { YES } \\
\text { P-Value = } \\
0.000\end{array}$ & YES & \begin{tabular}{l}
\multicolumn{1}{c}{ YES } \\
P-Value = \\
0.010
\end{tabular} & YES & \begin{tabular}{l}
\multicolumn{1}{c}{ YES } \\
P-Value = \\
0.000
\end{tabular} \\
\hline $10 \% \mathrm{PP} / \mathrm{SS}$ & & & & & YES & $\begin{array}{l}\quad \text { YES } \\
\text { P-Value = } \\
0.008\end{array}$ & YES & \begin{tabular}{l}
\multicolumn{1}{c}{ NO } \\
P-Value = \\
0.102
\end{tabular} & YES & \begin{tabular}{l}
\multicolumn{1}{c}{ YES } \\
P-Value = \\
0.000
\end{tabular} \\
\hline $10 \% 55 \mathrm{D} / \mathrm{SS}$ & & & & & & & YES & \begin{tabular}{l}
\multicolumn{1}{c}{ NO } \\
P-Value = \\
0.158
\end{tabular} & NO & \begin{tabular}{l}
\multicolumn{1}{c}{ YES } \\
P-Value = \\
0.003
\end{tabular} \\
\hline $10 \% 75 \mathrm{D} / \mathrm{SS}$ & & & & & & & & & YES & \begin{tabular}{l}
\multicolumn{1}{c}{ YES } \\
P-Value = \\
0.000
\end{tabular} \\
\hline Silicone/SS & & & & & & & & & & \\
\hline
\end{tabular}

\subsubsection{Process Issues}

There were no outstanding issues concerning the Phase I data. After completing multiple sets of practice sample groups the process was considered optimized to reduce the variation as much as possible given the context of this study.

\section{2. $\quad$ Phase II Results}

\subsubsection{Statistical Summary}

Phase II data for each sample group is summarized in Table 7. Although not yet confirmed statistically, some tendencies were detected from the Phase II data. 
Table 7 - Phase II Bonding Shear Strength Data

\begin{tabular}{|c|c|c|c|c|}
\hline Sample Group & $\begin{array}{l}\text { Accelerated } \\
\text { Aging Solution }\end{array}$ & $\begin{array}{c}\text { Time Interval } \\
\text { (Weeks) }\end{array}$ & $\begin{array}{c}\text { Bond Shear } \\
\text { Strength Average } \\
(\mathrm{MPa})\end{array}$ & $\begin{array}{c}\text { Interval-to } \\
\text { Interval } \\
\text { Difference } \\
\end{array}$ \\
\hline PIBS & $\mathrm{H}_{2} \mathrm{O}_{2}$ & 0 & $0.407 \pm 0.048$ & \\
\hline PIBS & $\mathrm{H}_{2} \mathrm{O}_{2}$ & 2 & $0.363 \pm 0.052$ & 0.044 \\
\hline PIBS & $\mathrm{H}_{2} \mathrm{O}_{2}$ & 4 & $0.372 \pm 0.059$ & -0.009 \\
\hline PIBS & $\mathrm{H}_{2} \mathrm{O}_{2}$ & 6 & $0.332 \pm 0.037$ & 0.040 \\
\hline PIBS & $\mathrm{H}_{2} \mathrm{O}_{2}$ & 8 & $0.293 \pm 0.027$ & 0.039 \\
\hline PIBS & PBS & 0 & $0.407 \pm 0.048$ & \\
\hline PIBS & PBS & 2 & $0.400 \pm 0.079$ & 0.007 \\
\hline PIBS & PBS & 4 & $0.385 \pm 0.023$ & 0.015 \\
\hline PIBS & PBS & 6 & $0.396 \pm 0.030$ & -0.011 \\
\hline PIBS & PBS & 8 & $0.380 \pm 0.053$ & 0.016 \\
\hline $10 \% \mathrm{PP}$ & $\mathrm{H}_{2} \mathrm{O}_{2}$ & 0 & $0.431 \pm 0.090$ & \\
\hline $10 \% \mathrm{PP}$ & $\mathrm{H}_{2} \mathrm{O}_{2}$ & 2 & $0.375 \pm 0.046$ & 0.061 \\
\hline $10 \% \mathrm{PP}$ & $\mathrm{H}_{2} \mathrm{O}_{2}$ & 4 & $0.310 \pm 0.086$ & 0.065 \\
\hline $10 \% \mathrm{PP}$ & $\mathrm{H}_{2} \mathrm{O}_{2}$ & 6 & $0.309 \pm 0.042$ & 0.001 \\
\hline $10 \% \mathrm{PP}$ & $\mathrm{H}_{2} \mathrm{O}_{2}$ & 8 & $0.293 \pm 0.067$ & 0.016 \\
\hline $10 \% \mathrm{PP}$ & PBS & 0 & $0.431 \pm 0.090$ & \\
\hline $10 \% \mathrm{PP}$ & PBS & 2 & $0.396 \pm 0.050$ & 0.035 \\
\hline $10 \% \mathrm{PP}$ & PBS & 4 & $0.385 \pm 0.023$ & 0.011 \\
\hline $10 \% \mathrm{PP}$ & PBS & 6 & $0.425 \pm 0.044$ & -0.040 \\
\hline $10 \% \mathrm{PP}$ & PBS & 8 & $0.411 \pm 0.085$ & 0.014 \\
\hline $10 \% 55 \mathrm{D}$ & $\mathrm{H}_{2} \mathrm{O}_{2}$ & 0 & $0.560 \pm 0.036$ & \\
\hline $10 \% 55 \mathrm{D}$ & $\mathrm{H}_{2} \mathrm{O}_{2}$ & 2 & $0.521 \pm 0.062$ & 0.039 \\
\hline $10 \% 55 \mathrm{D}$ & $\mathrm{H}_{2} \mathrm{O}_{2}$ & 4 & $0.479 \pm 0.029$ & 0.042 \\
\hline $10 \% 55 \mathrm{D}$ & $\mathrm{H}_{2} \mathrm{O}_{2}$ & 6 & $0.390 \pm 0.028$ & 0.089 \\
\hline $10 \% 55 \mathrm{D}$ & $\mathrm{H}_{2} \mathrm{O}_{2}$ & 8 & $0.336 \pm 0.016$ & 0.054 \\
\hline $10 \% 55 \mathrm{D}$ & PBS & 0 & $0.560 \pm 0.036$ & \\
\hline $10 \% 55 \mathrm{D}$ & PBS & 2 & $0.550 \pm 0.043$ & 0.010 \\
\hline $10 \% 55 \mathrm{D}$ & PBS & 4 & $0.559 \pm 0.029$ & -0.009 \\
\hline $10 \% 55 \mathrm{D}$ & PBS & 6 & $0.570 \pm 0.071$ & -0.011 \\
\hline
\end{tabular}




\begin{tabular}{|c|c|c|c|c|}
\hline $10 \% 55 \mathrm{D}$ & PBS & 8 & $0.552 \pm 0.028$ & 0.018 \\
\hline $10 \% 75 \mathrm{D}$ & $\mathrm{H}_{2} \mathrm{O}_{2}$ & 0 & $0.513 \pm 0.066$ & \\
\hline $10 \% 75 \mathrm{D}$ & $\mathrm{H}_{2} \mathrm{O}_{2}$ & 2 & $0.480 \pm 0.029$ & 0.033 \\
\hline $10 \% 75 \mathrm{D}$ & $\mathrm{H}_{2} \mathrm{O}_{2}$ & 4 & $0.418 \pm 0.065$ & 0.062 \\
\hline $10 \% 75 \mathrm{D}$ & $\mathrm{H}_{2} \mathrm{O}_{2}$ & 6 & $0.387 \pm 0.082$ & 0.031 \\
\hline $10 \% 75 \mathrm{D}$ & $\mathrm{H}_{2} \mathrm{O}_{2}$ & 8 & $0.355 \pm 0.039$ & 0.032 \\
\hline $10 \% 75 \mathrm{D}$ & PBS & 0 & $0.513 \pm 0.066$ & \\
\hline $10 \% 75 \mathrm{D}$ & PBS & 2 & $0.501 \pm 0.034$ & 0.012 \\
\hline $10 \% 75 \mathrm{D}$ & PBS & 4 & $0.510 \pm 0.078$ & -0.009 \\
\hline $10 \% 75 \mathrm{D}$ & PBS & 6 & $0.470 \pm 0.039$ & 0.040 \\
\hline $10 \% 75 \mathrm{D}$ & PBS & 8 & $0.448 \pm 0.022$ & 0.022 \\
\hline Silicone & $\mathrm{H}_{2} \mathrm{O}_{2}$ & 0 & $0.785 \pm 0.111$ & \\
\hline Silicone & $\mathrm{H}_{2} \mathrm{O}_{2}$ & 2 & $0.860 \pm 0.112$ & -0.075 \\
\hline Silicone & $\mathrm{H}_{2} \mathrm{O}_{2}$ & 4 & $0.878 \pm 0.101$ & -0.018 \\
\hline Silicone & $\mathrm{H}_{2} \mathrm{O}_{2}$ & 6 & $0.781 \pm 0.059$ & 0.097 \\
\hline Silicone & $\mathrm{H}_{2} \mathrm{O}_{2}$ & 8 & $0.772 \pm 0.100$ & 0.009 \\
\hline Silicone & PBS & 0 & $0.785 \pm 0.111$ & \\
\hline Silicone & PBS & 2 & $0.837 \pm 0.086$ & -0.052 \\
\hline Silicone & PBS & 4 & $0.835 \pm 0.105$ & 0.002 \\
\hline Silicone & PBS & 6 & $0.801 \pm 0.077$ & 0.034 \\
\hline Silicone & PBS & 8 & $0.814 \pm 0.095$ & -0.013 \\
\hline
\end{tabular}


Artificial aging results for the PIBS/SS silicone bond degraded a great deal more from the $\mathrm{H}_{2} \mathrm{O}_{2}$ solution than from the PBS solution (Figure 10). With an initial mean bonding shear strength of $0.407 \pm 0.048 \mathrm{MPa}$, PIBS/SS in $\mathrm{H}_{2} \mathrm{O}_{2}$ only showed a $28.0 \%$ decrease in bonding shear strength over the 8 -week period to end at $0.293 \pm 0.027 \mathrm{MPa}$. The PIBS/SS bonds in PBS over 8 weeks resulted in a $6.6 \%$ decrease in average bonding shear strength to $0.380 \pm 0.053 \mathrm{MPa}$.

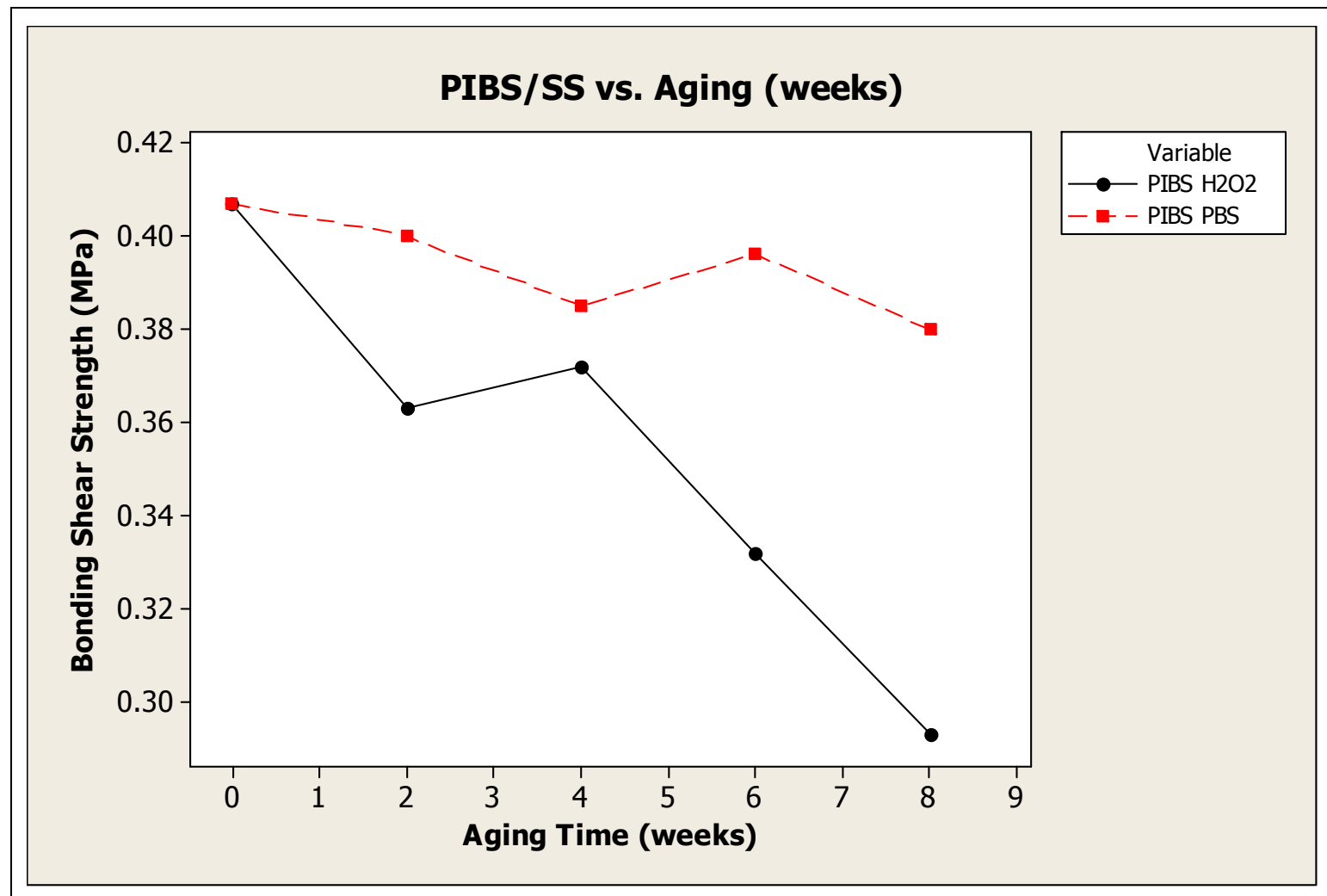

Figure 10. PIBS/SS Bonding Shear Strength (MPa) vs. Aging Time (weeks) for PBS and $\mathrm{H}_{2} \mathrm{O}_{2}$ 
The 10\% PP/SS group also showed greater degradation from the $\mathrm{H}_{2} \mathrm{O}_{2}$ solution compared to the PBS solution (Figure 11). When subjected to the PBS solution over 8 weeks the average bonding shear strength decreased from $0.431 \pm 0.090 \mathrm{MPa}$ to $0.411 \pm 0.085 \mathrm{MPa}$, which is only a 4.6\% overall decrease. The 10\%PP in PBS trend showed an initial decrease in value, then a subsequent increase over the 4-6 week time interval. $10 \% \mathrm{PP}$ in $\mathrm{H}_{2} \mathrm{O}_{2}$ solution resulted in a $32.0 \%$ 8-week decrease, from $0.431 \pm 0.090 \mathrm{MPa}$ to $0.293 \pm 0.067 \mathrm{MPa}$. The $\mathrm{H}_{2} \mathrm{O}_{2}$ aging showed a relatively slow initial decrease, which dramatically increased from during the 4 to 8 week period.

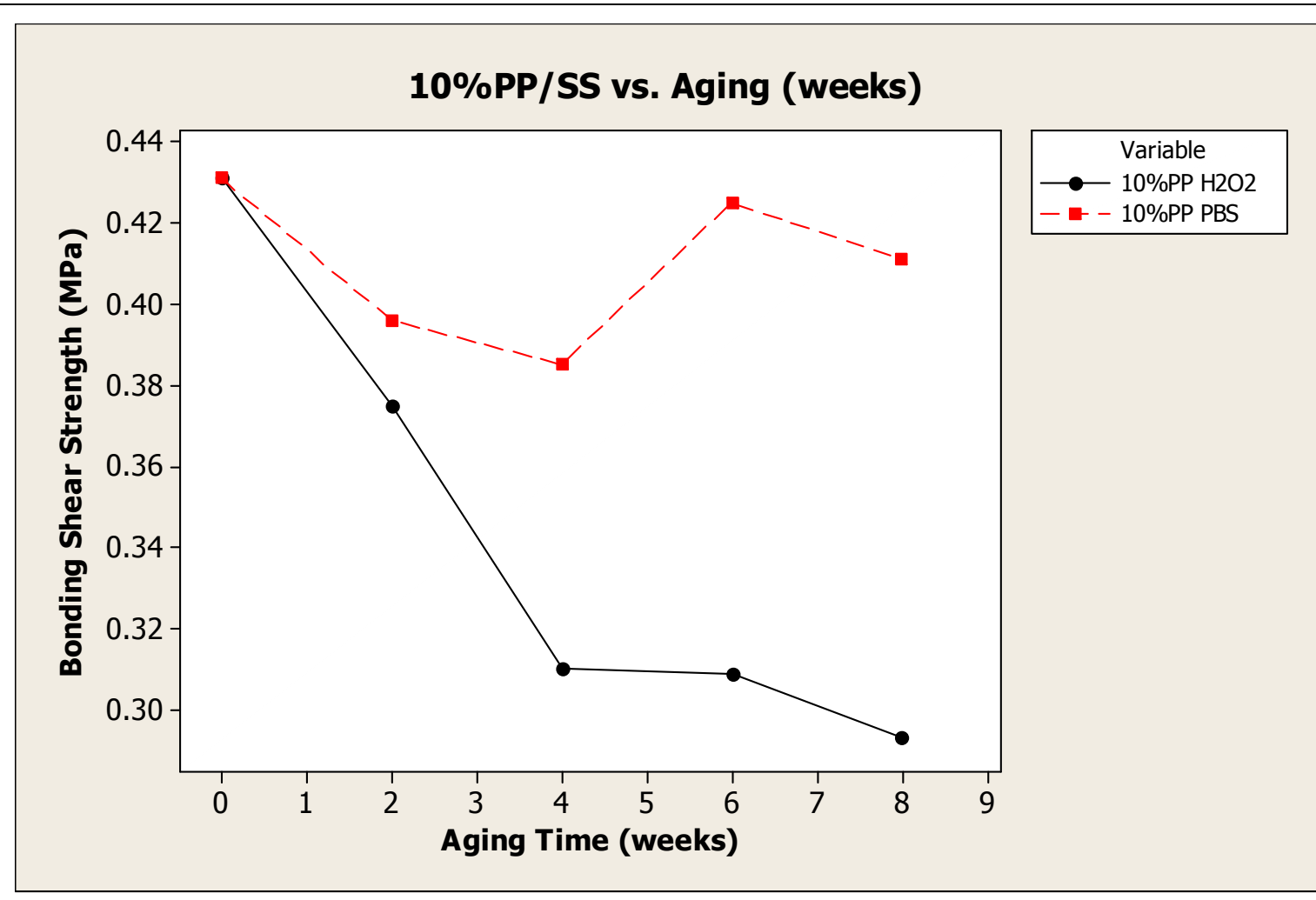

Figure 11. $10 \% \mathrm{PP} / \mathrm{SS}$ Bonding Shear Strength (MPa) vs. Aging Time (weeks) for PBS and $\mathrm{H}_{2} \mathrm{O}_{2}$ 
The $10 \% 55 \mathrm{D}$ polyurethane sample group displayed a similar trend to the $10 \% \mathrm{PP}$ and PIBS groups (Figure 12). Degradation from $\mathrm{H}_{2} \mathrm{O}_{2}$ was much more relevant than PBS. With an initial value of $0.560 \pm 0.036 \mathrm{MPa}$, the $10 \% 55 \mathrm{D}$ sample group decreased by $40 \%$ over 8 -weeks to $0.336 \pm 0.016 \mathrm{MPa}$. Also, the rate of decrease looked much more linear than the previous two sample groups. The 8-week mean bonding shear strength of $10 \% 55 \mathrm{D}$ in PBS solution was $0.552 \pm 0.028 \mathrm{MPa}$, only a $1.4 \%$ decrease over the accelerated aging study period.

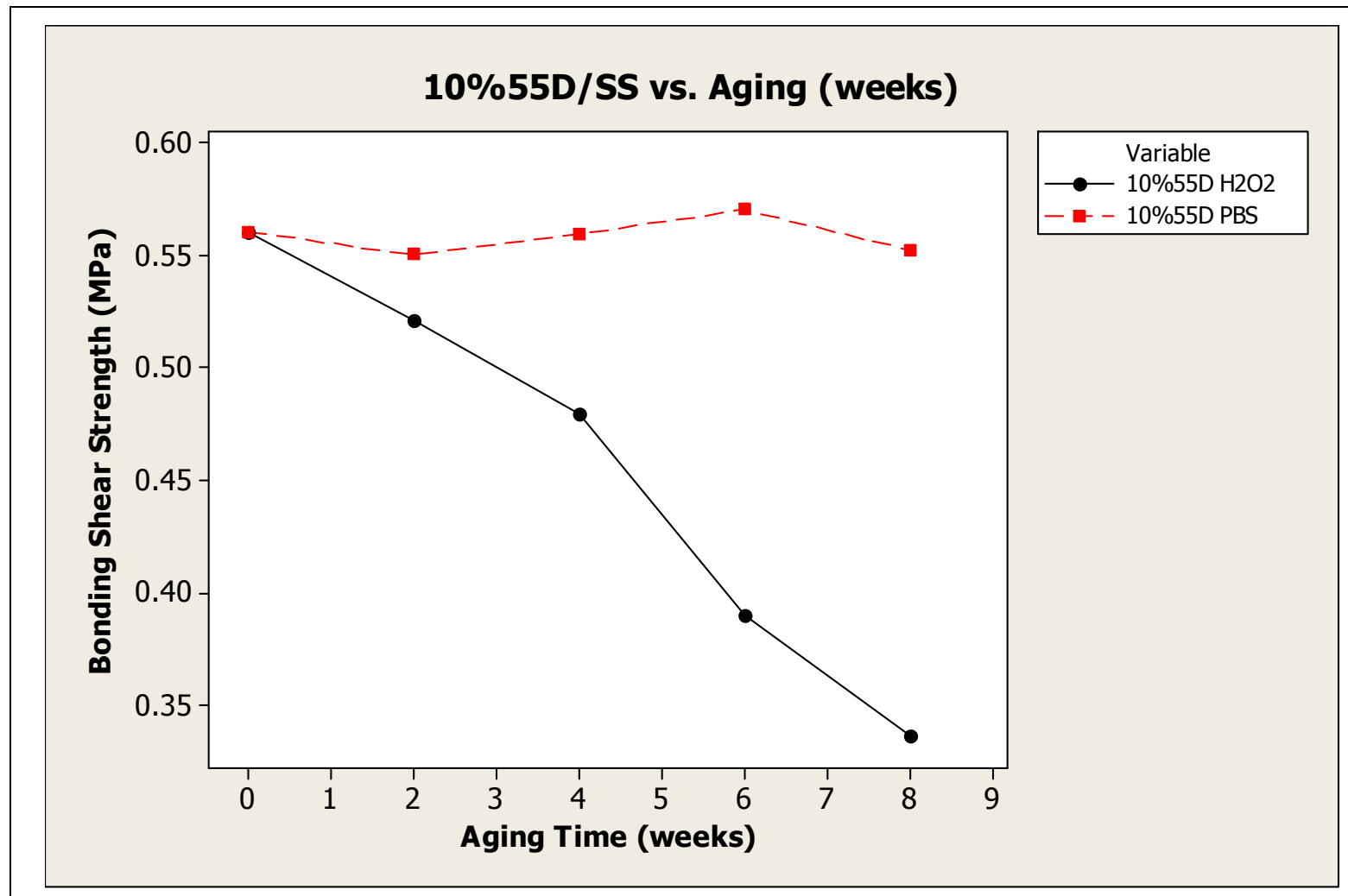

Figure 12. $10 \% 55 \mathrm{D} / \mathrm{SS}$ Bonding Shear Strength (MPa) vs. Aging Time (weeks) for PBS and $\mathrm{H}_{2} \mathrm{O}_{2}$ 
Similar to the $10 \% 55 \mathrm{D}$ sample group, $10 \% 75 \mathrm{D}$ showed a fairly linear decrease in mean bonding shear strength over the 8-week time interval in $\mathrm{H}_{2} \mathrm{O}_{2}$ (Figure 13). The 8-week value was $0.355 \pm 0.039 \mathrm{MPa}$, which was a $30.8 \%$ decrease from the initial mean bonding shear strength of $0.513 \pm 0.066 \mathrm{MPa} .10 \% 75 \mathrm{D}$ in PBS solution also resulted in a decrease in mean bonding shear strength from $0.513 \pm 0.066 \mathrm{MPa}$ to $0.448 \pm 0.022 \mathrm{MPa}$. This $12.7 \%$ decrease will be shown to be statistically significant or insignificant in the statistical analysis part of this section.

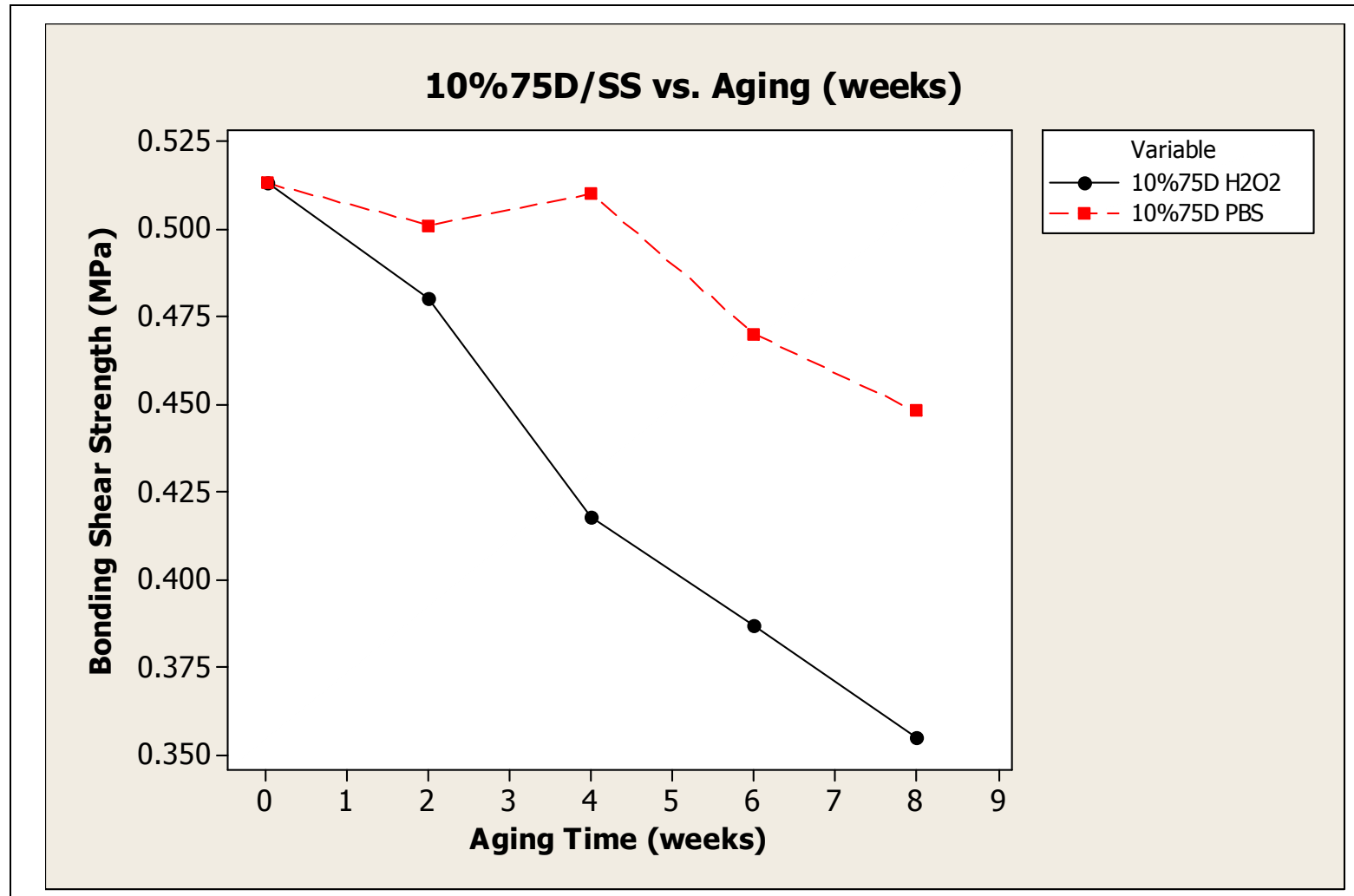

Figure 13. $10 \% 75 \mathrm{D} / \mathrm{SS}$ Bonding Shear Strength (MPa) vs. Aging Time (weeks) for PBS and $\mathrm{H}_{2} \mathrm{O}_{2}$ 
The Silicone/SS control group, also subjected to $\mathrm{H}_{2} \mathrm{O}_{2}$ and PBS, displayed similar trends for both solutions (Figure 14). Both with an initial mean bonding shear strength of $0.785 \pm 0.111$ $\mathrm{MPa}$, the sample group decreased to a value of $0.772 \pm 0.100 \mathrm{MPa}(1.7 \%)$ in $\mathrm{H}_{2} \mathrm{O}_{2}$ solution and actually increased to $0.814 \pm 0.095 \mathrm{MPa}$ in PBS solution (5.4\%). Because the silicone control group was not expected to degrade via hydrolysis or oxidation, the degradation rates were expected to be less volatile.

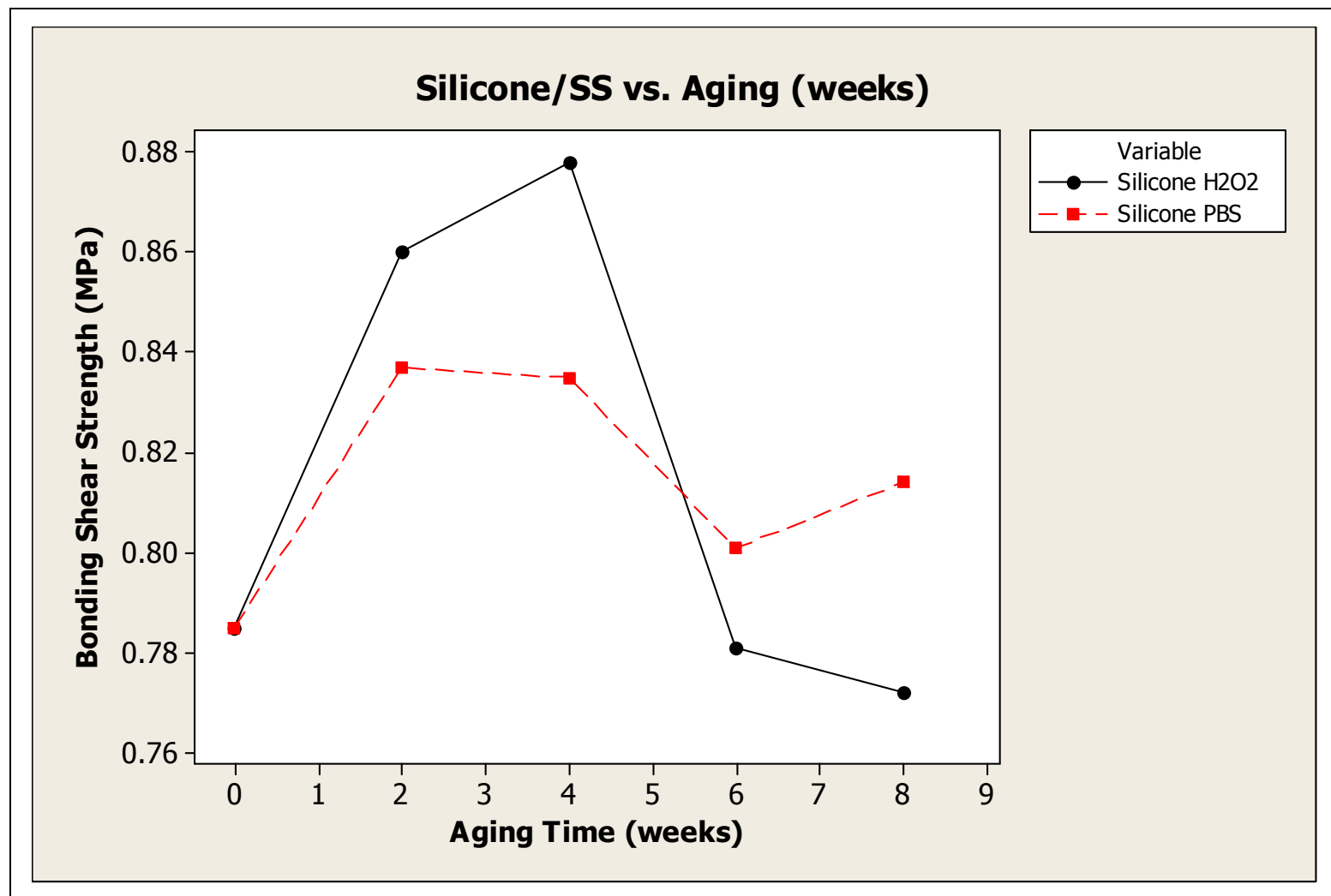

Figure 14. Silicone/SS Bonding Shear Strength (MPa) vs. Aging Time (weeks) for PBS and $\mathrm{H}_{2} \mathrm{O}_{2}$ 
Week 8 bonding shear strengths are summarized by Figure 15. Although the 10\%55D sample group had the highest initial mean bonding shear strength of $0.560 \mathrm{MPa}$, the $10 \% 75 \mathrm{D}$ sample group had the highest 8-week $\mathrm{H}_{2} \mathrm{O}_{2}$ value at $0.355 \mathrm{MPa}$.

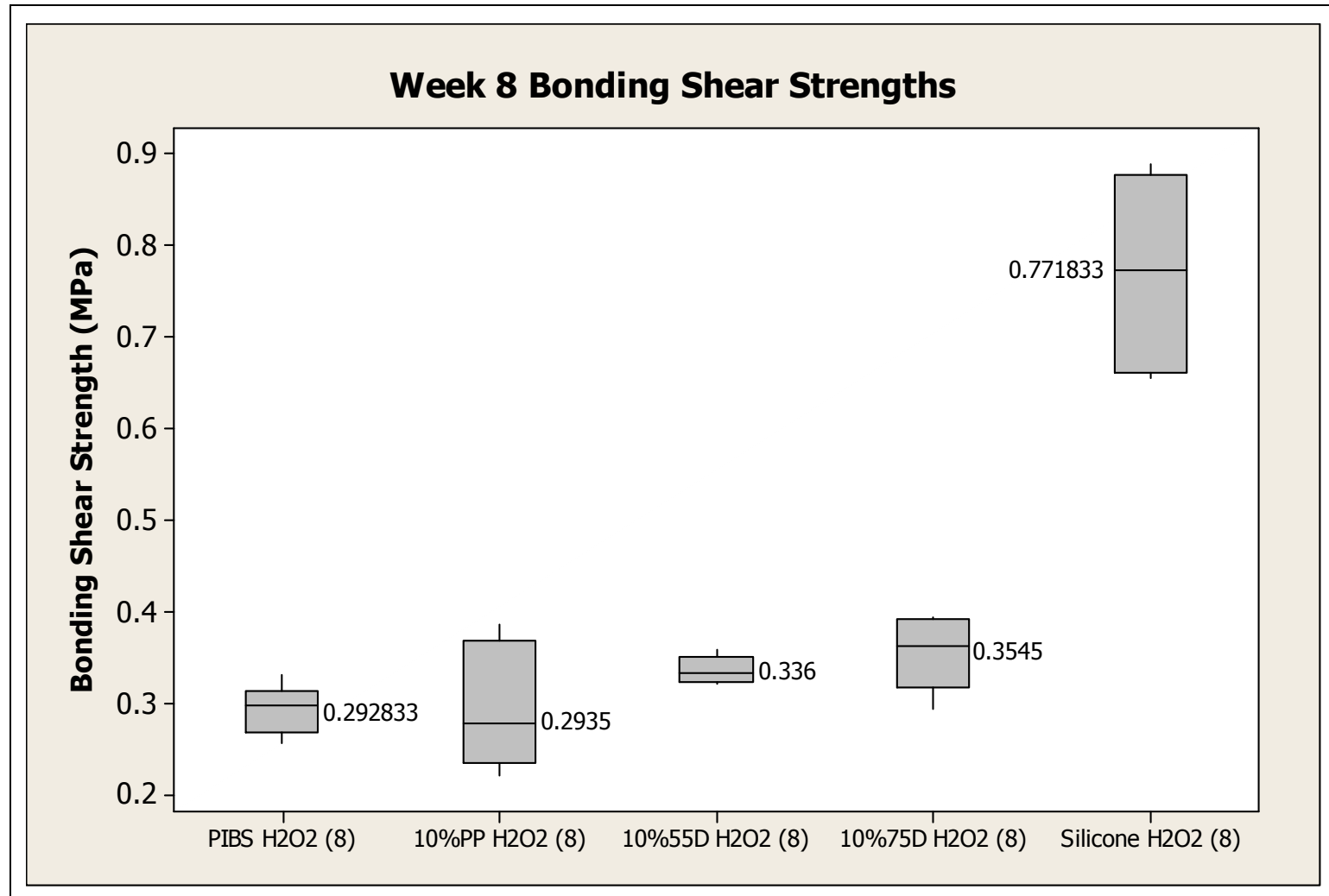

Figure 15. Week 8 Box Plots of Bonding Shear Strengths 


\subsubsection{Statistical Analysis}

Similar to Phase I, the data from Phase II was subjected to two sample t-tests to determine the significance of degradation. T-tests were performed between each sample group (material/chemical solution) for the mean bonding shear strengths at 8 weeks and 0 weeks.

Again, all sets of data were confirmed to be normal using the Anderson-Darling test for normality with $95 \%$ confidence. Tests for equal variances between 8 -week and 0 -week values were conducted for all data sets. All variances were equal with $95 \%$ confidence except for the 10\%75D/SS: 8 weeks vs. 0 weeks (PBS) sample group. T-test results are shown in Table 8.

Table 8 - Two Sample T-Test Results for Difference in Mean Bonding Shear Strength Between Week 0 and Week 8

\begin{tabular}{|c|c|c|c|c|c|}
\hline Sample Group & Normal? & $\begin{array}{c}\text { Equal } \\
\text { Variances? }\end{array}$ & $\begin{array}{l}\text { T-test p- } \\
\text { value }\end{array}$ & $\begin{array}{l}\text { Significant } \\
\text { Difference }\end{array}$ & $\begin{array}{c}\text { Overall } \\
\text { Difference }\end{array}$ \\
\hline $\begin{array}{l}\text { PIBS/SS: } 8 \text { weeks vs. } \\
0 \text { weeks }\left(\mathrm{H}_{2} \mathrm{O}_{2}\right)\end{array}$ & YES & YES & 0.000 & Yes & 0.114 \\
\hline $\begin{array}{l}\text { PIBS/SS: } 8 \text { weeks vs. } \\
0 \text { weeks }(\mathrm{PBS})\end{array}$ & YES & YES & 0.394 & No & 0.027 \\
\hline $\begin{array}{l}10 \% \mathrm{PP} / \mathrm{SS}: 8 \text { weeks } \\
\text { vs. } 0 \text { weeks }\left(\mathrm{H}_{2} \mathrm{O}_{2}\right)\end{array}$ & YES & YES & 0.013 & Yes & 0.138 \\
\hline $\begin{array}{l}\text { 10\%PP/SS: } 8 \text { weeks } \\
\text { vs. } 0 \text { weeks }(\mathrm{PBS})\end{array}$ & YES & YES & 0.698 & No & 0.020 \\
\hline $\begin{array}{l}10 \% 55 \mathrm{D} / \mathrm{SS}: 8 \text { weeks } \\
\text { vs. } 0 \text { weeks }\left(\mathrm{H}_{2} \mathrm{O}_{2}\right)\end{array}$ & YES & YES & 0.000 & Yes & 0.224 \\
\hline $\begin{array}{l}\text { 10\%55D/SS: } 8 \text { weeks } \\
\text { vs. } 0 \text { weeks }(\mathrm{PBS})\end{array}$ & YES & YES & 0.682 & No & 0.008 \\
\hline $\begin{array}{l}\text { 10\%75D/SS: } 8 \text { weeks } \\
\text { vs. } 0 \text { weeks }\left(\mathrm{H}_{2} \mathrm{O}_{2}\right)\end{array}$ & YES & YES & 0.000 & Yes & 0.158 \\
\hline $\begin{array}{l}\text { 10\%75D/SS: } 8 \text { weeks } \\
\text { vs. } 0 \text { weeks (PBS) }\end{array}$ & YES & NO & 0.061 & No & 0.065 \\
\hline $\begin{array}{l}\text { Silicone/SS: } 8 \text { weeks } \\
\text { vs. } 0 \text { weeks }\left(\mathrm{H}_{2} \mathrm{O}_{2}\right)\end{array}$ & YES & YES & 0.829 & No & 0.013 \\
\hline $\begin{array}{l}\text { Silicone/SS: } 8 \text { weeks } \\
\text { vs. } 0 \text { weeks }(\mathrm{PBS})\end{array}$ & YES & YES & 0.638 & No & -0.029 \\
\hline
\end{tabular}


The Phase II hypothesis test is as follows:

$\mathrm{H}_{0}$ : There is no difference between the 8-week and 0week mean bonding shear strength

$\mathrm{H}_{1}$ : There is a difference between the 8-week and 0-week mean bonding shear strength

A p-value less than 0.050 indicates that there is a significant difference between the mean bonding shear strength values at 8 -weeks and 0 -weeks with $95 \%$ confidence, so the null hypothesis should be rejected. A p-value greater than 0.050 signifies no significant difference between sample groups at 8-weeks and 0-weeks and the null hypothesis should not be rejected.

The t-test results show that each of the four sample groups were significantly degraded over the 8-week period by the hydrogen peroxide solution by p-values all less than 0.050 . Conversely, p-values for degradation from the phosphate buffered saline solution did not show significance for any sample groups. The silicone control displayed no significant degradation for either $\mathrm{H}_{2} \mathrm{O}_{2}$ or PBS (p-values greater than 0.050 ).

\subsubsection{Process Issues}

No significant issues 


\section{DISCUSSION}

\subsection{Phase I - Initial Bonding Shear Strength}

Results from Phase I demonstrated the ability of the silicone adhesive, with the assist of a primer, to bond to the low surface energy polymers and stainless steel. The mechanisms of silicone bonding include surface energy and chemical reactivity. Surface energy is the thermodynamic effect related to a material's intramolecular forces, which is a determining factor in how an adhesive wets a surface. The term "wetting" refers to the adhesives ability to cover a surface and maximize the contact area by utilizing the attractive forces between the adhesive and bonding surface. The lower the contact angle between the adhesive and substrate, the better the "wetting". A low contact angle increases the contact surface area and allows more oxygen containing groups ( $\mathrm{OH}$ groups) on the surface of plastics to bond to the adhesive and primer (Figure 16). For adequate wetting, it is commonly accepted that the substrate's surface energy must exceed that of the adhesive. Typically, a contact angle less than $90^{\circ}$ is considered good wetting. ${ }^{26}$

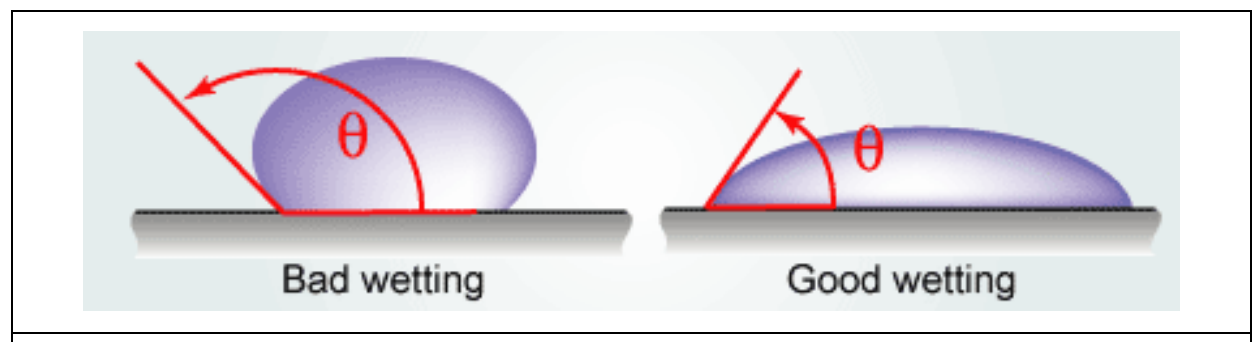

Figure 16. Wetting Angle of Adhesive on Substrate Showing Bad and Good ${ }^{27}$

Most polymers, including the materials in this study, are difficult to bond because of their low surface energy. The closeness of surface energy values between the substrates and silicone elastomer in this study justifies the need for the application of primer. Although primer application adds an extra step to the process, which will increase cycle time during manufacturing, it is necessary to attain adequate adhesion. Table 9 shows the surface energies of 
the materials observed in this study. Although the surface energies for the exact blends are not available, the characteristics of the homopolymers can be used to make conclusions about how the block copolymers will behave. This is considered an adequate method of analysis because block copolymers retain many of the physical characteristics of the homopolymers they are comprised of. ${ }^{25}$

Table 9 - Surface Energies of Relevant Materials

\begin{tabular}{|c|c|}
\hline MATERIAL & SURFACE ENERGY (dynes/cm) \\
\hline Silicone Elastomer & $22-24$ \\
\hline Stainless Steel & $700-1100$ \\
\hline PIBS & 27 \\
\hline Polypropylene & $29-31$ \\
\hline Polyurethane & 43 \\
\hline
\end{tabular}

Comparing the surface energies in Table 9 with the initial mean bonding shear strength values from Phase I, it is relevant to acknowledge the correlation between the two values. As the surface energy of the homopolymer that comprises the block copolymer increased, so did the mean bonding shear strength for the sample group (Figure 17). 


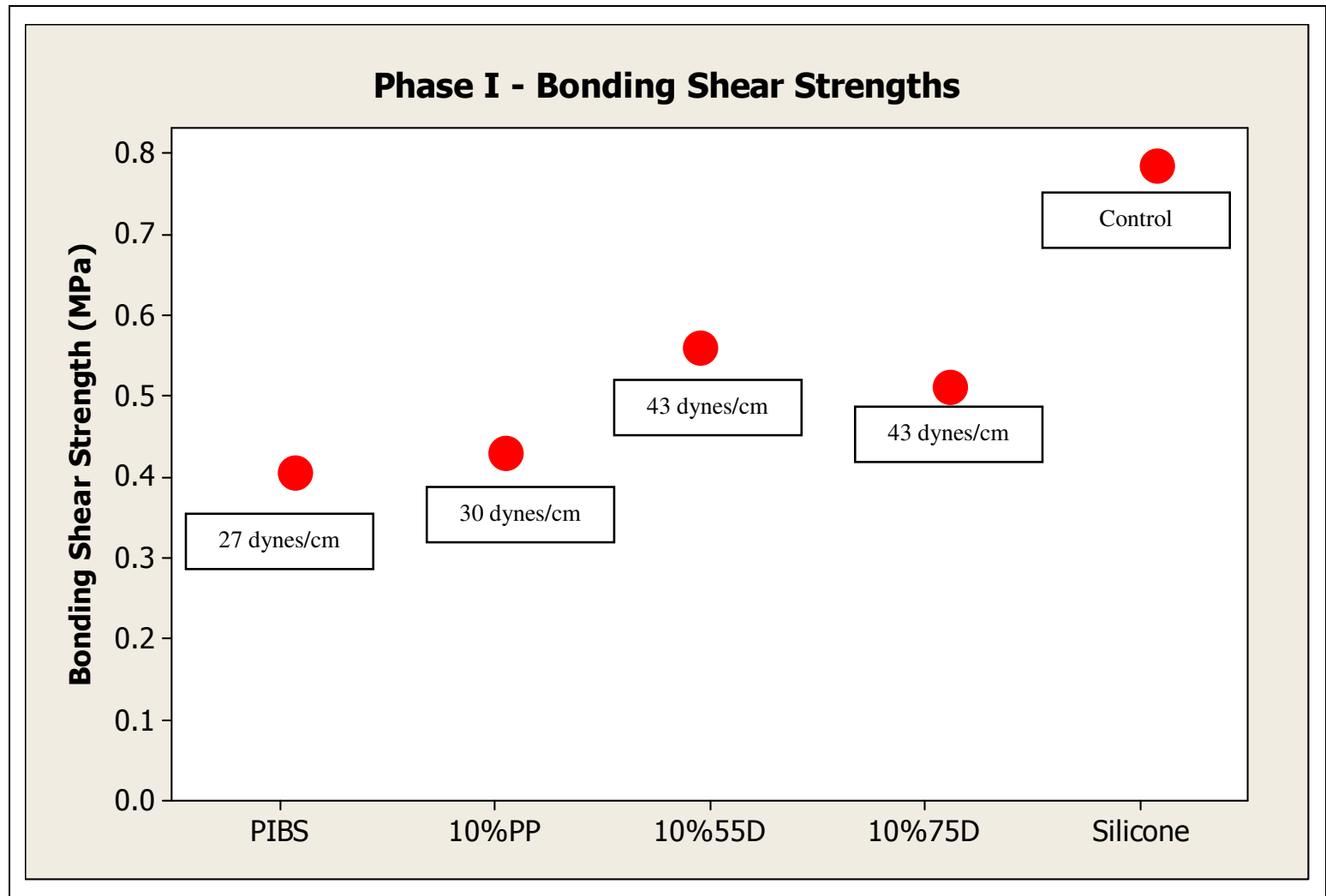

Figure 17. Initial Mean Bonding Shear Strengths with Relative Surface Energy Value

The PIBS tubing, which had the lowest surface energy (27 dynes/cm), also had the lowest mean bonding shear strength of $0.407 \mathrm{MPa}$. The $10 \% 55 \mathrm{D}$ and $10 \% 75 \mathrm{D}$ polyurethane/PIBS blends had the two highest mean bonding strength values, which were both upwards of $0.510 \mathrm{MPa}$.

Following the presumption that a higher surface energy will result in better wetting and a stronger bond, the polyurethane homopolymer that makes up part of the block copolymer also has the highest surface energy at 43 dynes/cm. It should also be noted that upon bond failure for the PIBS, $10 \% \mathrm{PP}, 10 \% 55 \mathrm{D}$, and $10 \% 75 \mathrm{D}$ samples, the silicone adhesive always remained attached to the stainless steel needle (Figure 18). 


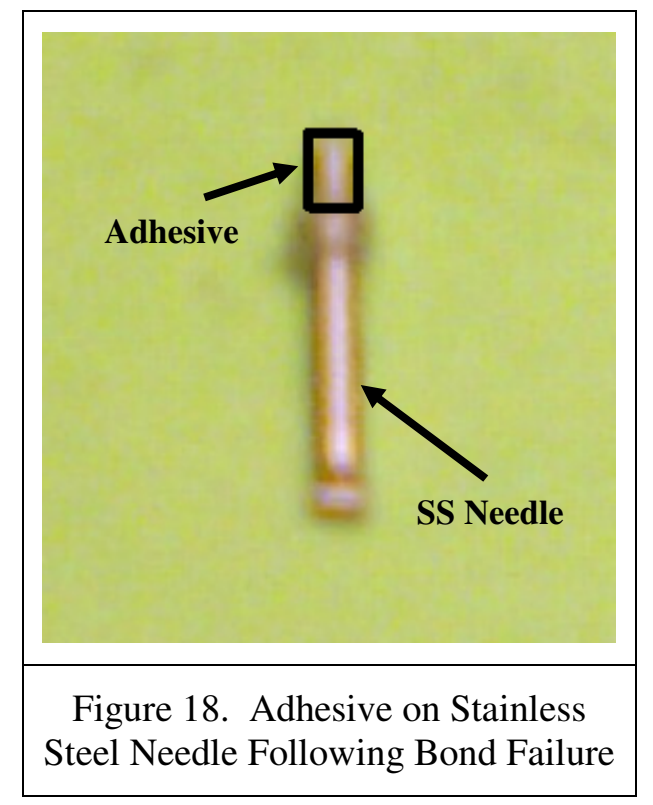

This supports the theory that a substrate with a higher surface energy will result in a stronger bond. The silicone adhesive remains on the stainless steel because the metal has a surface energy of $700-1100$ dynes $/ \mathrm{cm}$, which is at least fifteen times greater than any of the polymer substrates.

\section{2. $\quad$ Phase II - Aging Stability}

Results from Phase II of this study demonstrate that at least one component of the stainless steel/silicone adhesive/polymer tubing system degraded from prolonged exposure to the hydrogen peroxide solution causing a reduction in bond strength. All sample groups showed no significant degradation from the PBS solution. Because PIBS makes up the majority of each sample group, it is first important to understand its degradation characteristics before observing the affects of adding the polypropylene or polyurethane to each blend.

The two segments that make up the PIBS copolymer, polyisobutylene and polystyrene, are alkyl polymers, which are resistant to degradation by hydrolysis, or more specifically, hydrolytic chain cleavage. This phenomenon explains the lack of significant decrease in bonding shear strength for all sample groups over the 8 week period of submersion in PBS. Hydrolysis of 
the polypropylene and polyurethane PIBS blends was also insignificant. Polyolefins like polypropylene absorb very little water and contain no chemical bonds that are easily hydrolysable. As shown by the Phase II data, the addition of polypropylene to the PIBS blend does not increase hydrolytic degradation. Also, the Pellethane polyurethane that is blended with PIBS in the 10\%55D and 10\%75D sample groups is polyether based, which gives it good hydrolytic stability.

While the PIBS blends showed no significant hydrolytic degradation, the negative affect from oxidation caused by the $\mathrm{H}_{2} \mathrm{O}_{2}$ solution was a different story. The aromatic ring of the polystyrene block is easily oxidizable and resulted in a $28 \%$ decrease in bonding shear strength in Phase II of this study. ${ }^{4}$ Also, the oxidation of the 8-week PIBS samples was visibly recognizable by the yellow tinge, which is a sign that oxidation occurred. ${ }^{25}$

The addition of polypropylene and polyurethane to the PIBS showed a significant affect on the oxidative degradation of the relevant sample groups. The 10\% PP sample group showed a larger difference between week 8 and week 0 degradation than the PIBS sample group. The greater rate of oxidation with the addition of polypropylene may be due to its readily oxidizable tertiary hydrogen backbone. The two polyurethane blends, $10 \% 55 \mathrm{D}$ and $10 \% 75 \mathrm{D}$ groups also had a greater difference between the week 8 and week 0 degradation than the PIBS group. This can be explained by oxidation of the polyether chain where the most susceptible group is the $\mathrm{CH}_{2}$ group in the alpha position to the ether oxygen. This methyl group undergoes peroxidation, free radical dissociation, then chain cleavage, which leads to reduction in molecular weight and mechanical properties. ${ }^{29}$ The variation in degradation rate between the two PIBS/polyurethane blends, $10 \% 55 \mathrm{D}$ and $10 \% 75 \mathrm{D}$, can also be explained by the material properties of the copolymer's individual blocks. The $10 \% 55 \mathrm{D}$ sample group had a higher initial mean bonding shear strength, but degraded $40.0 \%$ over 8 -weeks in the hydrogen peroxide solution compared to 
$30.8 \%$ for the $10 \% 75 \mathrm{D}$ sample group. The lower percent degradation of $10 \% 75 \mathrm{D}$ can be explained by its higher hard segment content in comparison to $10 \% 55 \mathrm{D}$. Because oxidation occurs at the methyl group on the polyether soft segment chains, we can expect less degradation with less hard segment content. 


\section{CONCLUSION}

Although a preliminary step in the process toward commercialization, this study provides a foundation for the initial performance and aging stability for silicone bonding of PIBS and its blends as pacemaker lead insulation.

The material/primer/adhesive combination that had the strongest initial mean shearing bond strength was the 10\%55D sample group. The 10\%75D sample group, statistically, showed no significant difference compared to the $10 \% 55 \mathrm{D}$ group and can be considered equivalent. The strength of the PIBS/polyurethane samples was determined to be due to the relatively high surface energy in comparison to the other blended homopolymers. The PIBS and 10\%PP sample groups had a significantly lower mean bonding shear strength compared to the polyurethane blends, but were statistically similar to one another. This data also followed the surface energy relationship.

The phosphate buffered saline solution in Phase II caused no significant decrease in bonding shear strength for all sample groups. The lack of hydrolytic degradation can be explained by the alkyl groups that make up the blocks of the PIBS copolymer. The addition of polypropylene and polyurethane did not make the hydrolytic degradation significant because both of these homopolymers are inherently resistant to hydrolysis. Alternatively, oxidation caused by the $3 \%$ hydrogen peroxide solution did significantly affect the bonding shear strengths of all sample groups (minus the silicone control).

Although the PIBS blends exhibit better intrinsic mechanical properties (hardness and tear strength) in comparison to the silicone control group, the initial silicone bonding shear strength and resistance to oxidative degradation of all sample groups was inferior. Depending on the exact product specification for pacemakers and ICDs, the initial bonding shear strength of the polymer 
lead insulation to conducting coil and oxidative stability must be enhanced. Suggestions to accomplish these improvements include:

- $\quad$ The use of Design of Experiments (DOE) to optimize the bonding process. Process factors might include adhesive type, quantity, cure time, and application method, primer type, quantity, cure time and application method,

- $\quad$ Addition of surface treatments such as plasma and corona discharge. Plasma surface treatment has been known to reduce the wetting contact angle, which as seen in this study can improve the bonding shear strength. Corona discharge treatment has been used effectively as a pretreatment to increase adhesion.

Although a good simulation, accelerated aging cannot expose all of the mechanisms that may act on a device in vivo to cause deterioration of mechanical properties. The only true measure of acceptability of an implantable material is the study of its state, post-implant. 


\section{REFERENCES}

1. Atlee J, Bernstein A. 2001. Cardiac Rhythm Management Devices. American Society of Anesthesiologists. 95:1265-80

2. Schoenfeld M. 2007. Contemporary Pacemaker and Defibrillator Device Therapy: Challenges Confronting the General Cardiologist. Journal of the American Heart Association. 115: 638-653

3. Torpy J, Burke A, Glass R. 2006. Implantable Cardioverter Defibrillators. The Journal of the American Medical Association. 295; 15: 1964.

4. Ratner B, Hoffman A, Schoen F, Lemons J. 2004. Biomaterials Science: An Introduction to Materials in Medicine. San Diego, California. Elsevier Academic Press. 80-86, 411-430, 470-507,

5. http://www.health.uab.edu/

6. Hayes D, Lloyd M, Friedman P. 2000. Cardiac Pacing and Defibrillation. Blackwell Publishing. 11-18.

7. Wnek G, Bowlin G. 2004. Encyclopedia of Biomaterials and Biomedical Engineering. Informa Healthcare. 419-421.

8. Wiggins J, Wilkoff B, Anderson J, Hiltner A. 2001. Biodegradation of Polyether Polyurethane Inner Insulation in Bipolar Pacemaker Leads. Journal of Biomedical Materials Research. 58; 3: 302-307.

9. Voogt W. 1999. Pacemaker Leads: Performance and Progress. The American Journal of Cardiology. 83: 187D-191D.

10. Pacifico A, Henry P, Bardy G, Borggrefe M, Marchlinski F, Natale A, Wilkoff B. 2002. Implantable Defibrillator Therapy. Springer. 45-49.

11. Dow Corning Corporation. 2002-2005. SILASTIC BioMedical Grade ETR Elastomers (Q7-4780) Product Specification. Reference No. 52-1031B-01.

12. MatWeb for 75D Polyurethane

13. Story R, Chisholm B. 1993. Aspects of the Synthesis of Poly(StyreneIsobutylene-Styrene) Block Copolymers Using Living Carbocationic Polymerization. Macromolecules. 26: 6727-6733.

14. Kaneka Corporation. 2004. Kaneka Technical Information on StyreneIsobutylene Copolymer. Product Specification.

15. Kwee T, Taylor S, Mauritz K, Storey R. 2005. Morphology and Mechanical Dynamic Mechanical Properties of Linear and Star Poly(styrene-isobutylenestyrene) Block Copolymers. Polymer. 46: 4480-4491.

16. Lu X, Steckle W, Weiss R. 1993. Ionic Aggregation in a Block Copolymer Ionomer. Macromolecules. 26: 5876.

17. Salamone J. 1998. Concise Polymeric Materials Encyclopedia. CRC Press. 792793.

18. Kaneka Corporation. 2007. "Wholly Saturated” Styrene-Isobutylene-Styrene Block Copolymer. Product Brochure.

19. Canevaralo S. Handbook of Polymer Science and Technology. 599-600.

20. Packham D. 2005. Handbook of Adhesion. John Wiley and Sons. 467-473.

21. Ebnesajjad S. 2008. Adhesives Technology Handbook. William Andrew Inc. 118-120.

22. Nusil Technology. 2005. Med-2000 \& Med-1511 Silicone Adhesives. Product Profile. 
23. Rapra Technology Limited. 2006. Medical Polymers 2006. Rapra Technology. 1-3.

24. Nusil Technology. 2006. SP-135 High Technology Silicone Primer (Clear). Product Profile.

25. Allock H, Lampe F, Mark, J. 2003. Contemporary Polymer Chemistry. Pearson Education, Inc. 9-10, 170-172.

26. Rhodes K, Riegler B, Thomaier R. Silicone Adhesives and Primers on Low Surface Energy Plastics and High Strength Metals.

27. http://www.specialchem4adhesives.com/index.aspx

28. Ellenbogen K, Wood M. 2001. Cardiac Pacing and ICDs. Blackwell Publishing. 83-88.

29. Szycher M, McArthur W. Surface Fissuring of Polyurethanes Following in vivo Exposure. Corrosion and Degradation of Implant Materials. 1985. 308-321. 


\section{APPENDIX A}

\section{Phase I Data}

* $1.26 \mathrm{~mm}$ used for inside diameter

- all cure times $=71$ hours

\begin{tabular}{|c|c|c|c|c|}
\hline Material Combination & Replicate & Max Load (N) & $\begin{array}{c}\text { Tubing/SS } \\
\text { Overlap (mm) }\end{array}$ & $\begin{array}{l}\text { Bonding Shear } \\
\text { Strength (MPA)* }\end{array}$ \\
\hline PIBS/SS: SP-135 + Med2000 & 1 & 2.813 & 1.91 & 0.372 \\
\hline PIBS/SS: SP-135 + Med2000 & 2 & 3.221 & 1.92 & 0.424 \\
\hline PIBS/SS: SP-135 + Med2000 & 3 & 3.553 & 2.24 & 0.401 \\
\hline PIBS/SS: SP-135 + Med2000 & 4 & 2.982 & 1.84 & 0.409 \\
\hline PIBS/SS: SP-135 + Med2000 & 5 & 2.892 & 2.11 & 0.346 \\
\hline PIBS/SS: SP-135 + Med2000 & 6 & 3.743 & 1.94 & 0.487 \\
\hline $10 \%$ PP/SS: SP-135 + Med2000 & 1 & 4.294 & 1.82 & 0.596 \\
\hline 10\%PP/SS: SP-135 + Med2000 & 2 & 3.176 & 1.74 & 0.461 \\
\hline 10\%PP/SS: SP-135 + Med2000 & 3 & 2.936 & 1.92 & 0.386 \\
\hline 10\%PP/SS: SP-135 + Med2000 & 4 & 2.932 & 2.10 & 0.353 \\
\hline 10\%PP/SS: SP-135 + Med2000 & 5 & 3.427 & 2.04 & 0.424 \\
\hline 10\%PP/SS: SP-135 + Med2000 & 6 & 2.94 & 2.02 & 0.368 \\
\hline $10 \% 55 \mathrm{D} / \mathrm{SS}: \mathrm{SP}-135+\mathrm{Med} 2000$ & 1 & 4.693 & 2.00 & 0.593 \\
\hline $10 \% 55 \mathrm{D} / \mathrm{SS}: \mathrm{SP}-135+\mathrm{Med} 2000$ & 2 & 4.547 & 1.91 & 0.601 \\
\hline 10\%55D/SS: SP-135 +Med2000 & 3 & 4.786 & 2.26 & 0.535 \\
\hline 10\%55D/SS: SP-135 +Med2000 & 4 & 4.882 & 2.18 & 0.566 \\
\hline $10 \% 55 \mathrm{D} / \mathrm{SS}: \mathrm{SP}-135+\mathrm{Med} 2000$ & 5 & 4.431 & 2.00 & 0.560 \\
\hline $10 \% 55 \mathrm{D} / \mathrm{SS}: \mathrm{SP}-135+\mathrm{Med} 2000$ & 6 & 4.611 & 2.30 & 0.506 \\
\hline 10\%75D/SS: SP-135 + Med2000 & 1 & 3.903 & 2.28 & 0.432 \\
\hline 10\%75D/SS: SP-135 + Med2000 & 2 & 5.114 & 2.26 & 0.572 \\
\hline 10\%75D/SS: SP-135 + Med2000 & 3 & 4.054 & 2.28 & 0.449 \\
\hline 10\%75D/SS: SP-135 + Med2000 & 4 & 4.745 & 2.02 & 0.593 \\
\hline 10\%75D/SS: SP-135 + Med2000 & 5 & 4.566 & 2.35 & 0.491 \\
\hline 10\%75D/SS: SP-135 + Med2000 & 6 & 4.556 & 2.12 & 0.543 \\
\hline Silicone/SS: Med2000 (no primer) & 1 & 6.819 & 2.28 & 0.756 \\
\hline Silicone/SS: Med2000 (no primer) & 2 & 4.636 & 1.86 & 0.630 \\
\hline Silicone/SS: Med2000 (no primer) & 3 & 6.706 & 2.25 & 0.753 \\
\hline Silicone/SS: Med2000 (no primer) & 4 & 7.833 & 2.04 & 0.970 \\
\hline Silicone/SS: Med2000 (no primer) & 5 & 6.604 & 2.12 & 0.787 \\
\hline Silicone/SS: Med2000 (no primer) & 6 & 5.685 & 1.76 & 0.816 \\
\hline
\end{tabular}


Phase II Data

\begin{tabular}{|c|c|c|c|c|c|c|}
\hline Material Combination & $\begin{array}{c}\begin{array}{c}\text { Aging } \\
\text { (weeks) }\end{array} \\
\end{array}$ & $\begin{array}{c}\text { Treatment } \\
\text { Media }\end{array}$ & Replicate & $\begin{array}{l}\text { Max Load } \\
(\mathrm{N})\end{array}$ & $\begin{array}{c}\text { Tubing/SS } \\
\text { Overlap } \\
\text { (mm) }\end{array}$ & $\begin{array}{l}\text { Bonding } \\
\text { Shear } \\
\text { Strength } \\
\text { (MPA)* }\end{array}$ \\
\hline $10 \% \mathrm{PP} / \mathrm{SS}$ & 2 & $\mathrm{H} 2 \mathrm{O} 2$ & 1 & 3.586 & 2.57 & 0.352 \\
\hline $10 \% \mathrm{PP} / \mathrm{SS}$ & 2 & $\mathrm{H} 2 \mathrm{O} 2$ & 2 & 3.149 & 2.23 & 0.357 \\
\hline $10 \% \mathrm{PP} / \mathrm{SS}$ & 2 & $\mathrm{H} 2 \mathrm{O} 2$ & 3 & 3.980 & 2.41 & 0.417 \\
\hline $10 \% \mathrm{PP} / \mathrm{SS}$ & 2 & $\mathrm{H} 2 \mathrm{O} 2$ & 4 & 4.117 & 2.37 & 0.439 \\
\hline $10 \% \mathrm{PP} / \mathrm{SS}$ & 2 & $\mathrm{H} 2 \mathrm{O} 2$ & 5 & 3.277 & 2.22 & 0.373 \\
\hline $10 \% \mathrm{PP} / \mathrm{SS}$ & 2 & $\mathrm{H} 2 \mathrm{O} 2$ & 6 & 2.671 & 2.15 & 0.314 \\
\hline $10 \% \mathrm{PP} / \mathrm{SS}$ & 2 & PBS & 1 & 4.267 & 2.34 & 0.461 \\
\hline $10 \% \mathrm{PP} / \mathrm{SS}$ & 2 & PBS & 2 & 3.227 & 2.53 & 0.322 \\
\hline $10 \% \mathrm{PP} / \mathrm{SS}$ & 2 & PBS & 3 & 3.683 & 2.22 & 0.419 \\
\hline $10 \% \mathrm{PP} / \mathrm{SS}$ & 2 & PBS & 4 & 4.207 & 2.51 & 0.423 \\
\hline $10 \% \mathrm{PP} / \mathrm{SS}$ & 2 & PBS & 5 & 3.154 & 2.22 & 0.359 \\
\hline $10 \% \mathrm{PP} / \mathrm{SS}$ & 2 & PBS & 6 & 3.679 & 2.37 & 0.392 \\
\hline Silicone/SS & 2 & $\mathrm{H} 2 \mathrm{O} 2$ & 1 & 7.046 & 2.45 & 0.727 \\
\hline Silicone/SS & 2 & $\mathrm{H} 2 \mathrm{O} 2$ & 2 & 8.473 & 2.12 & 1.010 \\
\hline Silicone/SS & 2 & $\mathrm{H} 2 \mathrm{O} 2$ & 3 & 8.524 & 2.19 & 0.983 \\
\hline Silicone/SS & 2 & $\mathrm{H} 2 \mathrm{O} 2$ & 4 & 7.904 & 2.51 & 0.796 \\
\hline Silicone/SS & 2 & $\mathrm{H} 2 \mathrm{O} 2$ & 5 & 7.758 & 2.34 & 0.838 \\
\hline Silicone/SS & 2 & $\mathrm{H} 2 \mathrm{O} 2$ & 6 & 7.231 & 2.27 & 0.805 \\
\hline Silicone/SS & 2 & PBS & 1 & 8.282 & 2.15 & 0.973 \\
\hline Silicone/SS & 2 & PBS & 2 & 7.401 & 2.21 & 0.846 \\
\hline Silicone/SS & 2 & PBS & 3 & 7.756 & 2.3 & 0.852 \\
\hline Silicone/SS & 2 & PBS & 4 & 6.203 & 2.22 & 0.706 \\
\hline Silicone/SS & 2 & PBS & 5 & 7.298 & 2.27 & 0.812 \\
\hline Silicone/SS & 2 & PBS & 6 & 6.944 & 2.1 & 0.835 \\
\hline $10 \% 55 \mathrm{D} / \mathrm{SS}$ & 2 & $\mathrm{H} 2 \mathrm{O} 2$ & 1 & 4.673 & 2.35 & 0.502 \\
\hline $10 \% 55 \mathrm{D} / \mathrm{SS}$ & 2 & $\mathrm{H} 2 \mathrm{O} 2$ & 2 & 4.399 & 2.67 & 0.416 \\
\hline $10 \% 55 \mathrm{D} / \mathrm{SS}$ & 2 & $\mathrm{H} 2 \mathrm{O} 2$ & 3 & 4.681 & 1.95 & 0.606 \\
\hline $10 \% 55 \mathrm{D} / \mathrm{SS}$ & 2 & $\mathrm{H} 2 \mathrm{O} 2$ & 4 & 4.551 & 2.13 & 0.540 \\
\hline $10 \% 55 \mathrm{D} / \mathrm{SS}$ & 2 & $\mathrm{H} 2 \mathrm{O} 2$ & 5 & 4.583 & 2.19 & 0.529 \\
\hline $10 \% 55 \mathrm{D} / \mathrm{SS}$ & 2 & $\mathrm{H} 2 \mathrm{O} 2$ & 6 & 4.468 & 2.12 & 0.532 \\
\hline $10 \% 55 \mathrm{D} / \mathrm{SS}$ & 2 & PBS & 1 & 4.783 & 2.41 & 0.501 \\
\hline $10 \% 55 \mathrm{D} / \mathrm{SS}$ & 2 & PBS & 2 & 5.574 & 2.69 & 0.523 \\
\hline $10 \% 55 \mathrm{D} / \mathrm{SS}$ & 2 & PBS & 3 & 5.213 & 2.56 & 0.514 \\
\hline $10 \% 55 \mathrm{D} / \mathrm{SS}$ & 2 & PBS & 4 & 5.461 & 2.36 & 0.585 \\
\hline $10 \% 55 \mathrm{D} / \mathrm{SS}$ & 2 & PBS & 5 & 5.439 & 2.43 & 0.565 \\
\hline $10 \% 55 \mathrm{D} / \mathrm{SS}$ & 2 & PBS & 6 & 5.41 & 2.24 & 0.610 \\
\hline $\mathrm{PIBS} / \mathrm{SS}$ & 2 & $\mathrm{H} 2 \mathrm{O} 2$ & 1 & 3.502 & 2.19 & 0.404 \\
\hline PIBS/SS & 2 & $\mathrm{H} 2 \mathrm{O} 2$ & 2 & 3.771 & 2.29 & 0.416 \\
\hline $\mathrm{PIBS} / \mathrm{SS}$ & 2 & $\mathrm{H} 2 \mathrm{O} 2$ & 3 & 3.345 & 2.11 & 0.400 \\
\hline PIBS/SS & 2 & $\mathrm{H} 2 \mathrm{O} 2$ & 4 & 3.013 & 2.67 & 0.285 \\
\hline PIBS/SS & 2 & $\mathrm{H} 2 \mathrm{O} 2$ & 5 & 3.149 & 2.34 & 0.340 \\
\hline $\mathrm{PIBS} / \mathrm{SS}$ & 2 & $\mathrm{H} 2 \mathrm{O} 2$ & 6 & 3.288 & 2.51 & 0.331 \\
\hline $\mathrm{PIBS} / \mathrm{SS}$ & 2 & PBS & 1 & 4.518 & 2.21 & 0.516 \\
\hline
\end{tabular}




\begin{tabular}{|c|c|c|c|c|c|c|}
\hline PIBS/SS & 2 & PBS & 2 & 3.571 & 2.23 & 0.405 \\
\hline PIBS/SS & 2 & PBS & 3 & 2.496 & 2.19 & 0.288 \\
\hline PIBS/SS & 2 & PBS & 4 & 3.188 & 2.28 & 0.353 \\
\hline $\mathrm{PIBS} / \mathrm{SS}$ & 2 & PBS & 5 & 4.21 & 2.35 & 0.453 \\
\hline PIBS/SS & 2 & PBS & 6 & 3.346 & 2.21 & 0.382 \\
\hline $10 \% 75 \mathrm{D} / \mathrm{SS}$ & 2 & $\mathrm{H} 2 \mathrm{O} 2$ & 1 & 4.833 & 2.51 & 0.486 \\
\hline $10 \% 75 \mathrm{D} / \mathrm{SS}$ & 2 & $\mathrm{H} 2 \mathrm{O} 2$ & 2 & 4.51 & 2.62 & 0.435 \\
\hline $10 \% 75 \mathrm{D} / \mathrm{SS}$ & 2 & $\mathrm{H} 2 \mathrm{O} 2$ & 3 & 4.893 & 2.68 & 0.461 \\
\hline $10 \% 75 \mathrm{D} / \mathrm{SS}$ & 2 & $\mathrm{H} 2 \mathrm{O} 2$ & 4 & 5.509 & 2.88 & 0.483 \\
\hline $10 \% 75 \mathrm{D} / \mathrm{SS}$ & 2 & $\mathrm{H} 2 \mathrm{O} 2$ & 5 & 5.516 & 2.67 & 0.522 \\
\hline $10 \% 75 \mathrm{D} / \mathrm{SS}$ & 2 & $\mathrm{H} 2 \mathrm{O} 2$ & 6 & 5.783 & 2.98 & 0.490 \\
\hline $10 \% 75 \mathrm{D} / \mathrm{SS}$ & 2 & PBS & 1 & 4.248 & 2.35 & 0.457 \\
\hline $10 \% 75 \mathrm{D} / \mathrm{SS}$ & 2 & PBS & 2 & 5.773 & 2.67 & 0.546 \\
\hline $10 \% 75 \mathrm{D} / \mathrm{SS}$ & 2 & PBS & 3 & 4.967 & 2.43 & 0.516 \\
\hline $10 \% 75 \mathrm{D} / \mathrm{SS}$ & 2 & PBS & 4 & 4.832 & 2.39 & 0.511 \\
\hline $10 \% 75 \mathrm{D} / \mathrm{SS}$ & 2 & PBS & 5 & 5.135 & 2.79 & 0.465 \\
\hline $10 \% 75 \mathrm{D} / \mathrm{SS}$ & 2 & PBS & 6 & 5.124 & 2.54 & 0.510 \\
\hline $10 \% \mathrm{PP} / \mathrm{SS}$ & 4 & $\mathrm{H} 2 \mathrm{O} 2$ & 1 & 3.541 & 2.23 & 0.401 \\
\hline $10 \% \mathrm{PP} / \mathrm{SS}$ & 4 & $\mathrm{H} 2 \mathrm{O} 2$ & 2 & 2.588 & 2.01 & 0.325 \\
\hline $10 \% \mathrm{PP} / \mathrm{SS}$ & 4 & $\mathrm{H} 2 \mathrm{O} 2$ & 3 & 2.998 & 2.12 & 0.357 \\
\hline $10 \% \mathrm{PP} / \mathrm{SS}$ & 4 & $\mathrm{H} 2 \mathrm{O} 2$ & 4 & 2.059 & 2.27 & 0.229 \\
\hline $10 \% \mathrm{PP} / \mathrm{SS}$ & 4 & $\mathrm{H} 2 \mathrm{O} 2$ & 5 & 3.249 & 2.24 & 0.366 \\
\hline $10 \% \mathrm{PP} / \mathrm{SS}$ & 4 & $\mathrm{H} 2 \mathrm{O} 2$ & 6 & 1.701 & 2.36 & 0.182 \\
\hline $10 \% \mathrm{PP} / \mathrm{SS}$ & 4 & PBS & 1 & 2.396 & 2.19 & 0.276 \\
\hline $10 \% \mathrm{PP} / \mathrm{SS}$ & 4 & PBS & 2 & 2.925 & 2.08 & 0.355 \\
\hline $10 \% \mathrm{PP} / \mathrm{SS}$ & 4 & PBS & 3 & 3.661 & 2.34 & 0.395 \\
\hline $10 \% \mathrm{PP} / \mathrm{SS}$ & 4 & PBS & 4 & 3.942 & 2.31 & 0.431 \\
\hline $10 \% \mathrm{PP} / \mathrm{SS}$ & 4 & PBS & 5 & 4.13 & 2.21 & 0.472 \\
\hline $10 \% \mathrm{PP} / \mathrm{SS}$ & 4 & PBS & 6 & 4.079 & 2.27 & 0.454 \\
\hline Silicone/SS & 4 & $\mathrm{H} 2 \mathrm{O} 2$ & 1 & 7.183 & 2.3 & 0.789 \\
\hline Silicone/SS & 4 & $\mathrm{H} 2 \mathrm{O} 2$ & 2 & 6.136 & 2 & 0.775 \\
\hline Silicone/SS & 4 & $\mathrm{H} 2 \mathrm{O} 2$ & 3 & 7.198 & 2.08 & 0.874 \\
\hline Silicone/SS & 4 & $\mathrm{H} 2 \mathrm{O} 2$ & 4 & 8.983 & 2.26 & 1.004 \\
\hline Silicone/SS & 4 & $\mathrm{H} 2 \mathrm{O} 2$ & 5 & 7.036 & 2.14 & 0.831 \\
\hline Silicone/SS & 4 & $\mathrm{H} 2 \mathrm{O} 2$ & 6 & 8.004 & 2.03 & 0.996 \\
\hline Silicone/SS & 4 & PBS & 1 & 8.094 & 2.01 & 1.017 \\
\hline Silicone/SS & 4 & PBS & 2 & 7.485 & 2.11 & 0.896 \\
\hline Silicone/SS & 4 & PBS & 3 & 7.02 & 2.25 & 0.788 \\
\hline Silicone/SS & 4 & PBS & 4 & 7.097 & 2.21 & 0.811 \\
\hline Silicone/SS & 4 & PBS & 5 & 6.549 & 2.16 & 0.766 \\
\hline Silicone/SS & 4 & PBS & 6 & 6.326 & 2.19 & 0.730 \\
\hline $10 \% 55 \mathrm{D} / \mathrm{SS}$ & 4 & $\mathrm{H} 2 \mathrm{O} 2$ & 1 & 4.139 & 2.31 & 0.453 \\
\hline $10 \% 55 \mathrm{D} / \mathrm{SS}$ & 4 & $\mathrm{H} 2 \mathrm{O} 2$ & 2 & 4.22 & 2.16 & 0.494 \\
\hline $10 \% 55 \mathrm{D} / \mathrm{SS}$ & 4 & $\mathrm{H} 2 \mathrm{O} 2$ & 3 & 4.271 & 2.42 & 0.446 \\
\hline $10 \% 55 \mathrm{D} / \mathrm{SS}$ & 4 & $\mathrm{H} 2 \mathrm{O} 2$ & 4 & 4.285 & 2.08 & 0.520 \\
\hline $10 \% 55 \mathrm{D} / \mathrm{SS}$ & 4 & $\mathrm{H} 2 \mathrm{O} 2$ & 5 & 4.204 & 2.28 & 0.466 \\
\hline $10 \% 55 \mathrm{D} / \mathrm{SS}$ & 4 & $\mathrm{H} 2 \mathrm{O} 2$ & 6 & 4.194 & 2.15 & 0.493 \\
\hline $10 \% 55 \mathrm{D} / \mathrm{SS}$ & 4 & PBS & 1 & 4.39 & 2.09 & 0.531 \\
\hline
\end{tabular}




\begin{tabular}{|c|c|c|c|c|c|c|}
\hline $10 \% 55 \mathrm{D} / \mathrm{SS}$ & 4 & PBS & 2 & 4.713 & 2.29 & 0.520 \\
\hline $10 \% 55 \mathrm{D} / \mathrm{SS}$ & 4 & PBS & 3 & 4.845 & 2.17 & 0.564 \\
\hline $10 \% 55 \mathrm{D} / \mathrm{SS}$ & 4 & PBS & 4 & 4.985 & 2.13 & 0.591 \\
\hline $10 \% 55 \mathrm{D} / \mathrm{SS}$ & 4 & PBS & 5 & 4.818 & 2.08 & 0.585 \\
\hline $10 \% 55 \mathrm{D} / \mathrm{SS}$ & 4 & PBS & 6 & 4.899 & 2.2 & 0.563 \\
\hline PIBS/SS & 4 & $\mathrm{H} 2 \mathrm{O} 2$ & 1 & 4.039 & 2.21 & 0.462 \\
\hline PIBS/SS & 4 & $\mathrm{H} 2 \mathrm{O} 2$ & 2 & 3.275 & 2.16 & 0.383 \\
\hline PIBS/SS & 4 & $\mathrm{H} 2 \mathrm{O} 2$ & 3 & 3.328 & 2.23 & 0.377 \\
\hline PIBS/SS & 4 & $\mathrm{H} 2 \mathrm{O} 2$ & 4 & 3.219 & 2.22 & 0.366 \\
\hline PIBS/SS & 4 & $\mathrm{H} 2 \mathrm{O} 2$ & 5 & 3.123 & 2.13 & 0.370 \\
\hline PIBS/SS & 4 & $\mathrm{H} 2 \mathrm{O} 2$ & 6 & 2.464 & 2.26 & 0.275 \\
\hline PIBS/SS & 4 & PBS & 1 & 3.372 & 2.08 & 0.410 \\
\hline PIBS/SS & 4 & PBS & 2 & 3.096 & 2.07 & 0.378 \\
\hline PIBS/SS & 4 & PBS & 3 & 3.089 & 2.17 & 0.360 \\
\hline PIBS/SS & 4 & PBS & 4 & 3.128 & 2.02 & 0.391 \\
\hline PIBS/SS & 4 & PBS & 5 & 3.221 & 1.98 & 0.411 \\
\hline $\mathrm{PIBS} / \mathrm{SS}$ & 4 & PBS & 6 & 3.004 & 2.11 & 0.360 \\
\hline $10 \% 75 \mathrm{D} / \mathrm{SS}$ & 4 & $\mathrm{H} 2 \mathrm{O} 2$ & 1 & 3.338 & 2.18 & 0.387 \\
\hline $10 \% 75 \mathrm{D} / \mathrm{SS}$ & 4 & $\mathrm{H} 2 \mathrm{O} 2$ & 2 & 3.12 & 2.11 & 0.374 \\
\hline $10 \% 75 \mathrm{D} / \mathrm{SS}$ & 4 & $\mathrm{H} 2 \mathrm{O} 2$ & 3 & 4.136 & 2.13 & 0.491 \\
\hline $10 \% 75 \mathrm{D} / \mathrm{SS}$ & 4 & $\mathrm{H} 2 \mathrm{O} 2$ & 4 & 3.164 & 2.43 & 0.329 \\
\hline $10 \% 75 \mathrm{D} / \mathrm{SS}$ & 4 & $\mathrm{H} 2 \mathrm{O} 2$ & 5 & 4.096 & 2.14 & 0.484 \\
\hline $10 \% 75 \mathrm{D} / \mathrm{SS}$ & 4 & $\mathrm{H} 2 \mathrm{O} 2$ & 6 & 4.037 & 2.28 & 0.447 \\
\hline $10 \% 75 \mathrm{D} / \mathrm{SS}$ & 4 & PBS & 1 & 5.485 & 2.37 & 0.585 \\
\hline $10 \% 75 \mathrm{D} / \mathrm{SS}$ & 4 & PBS & 2 & 3.63 & 2.05 & 0.447 \\
\hline $10 \% 75 \mathrm{D} / \mathrm{SS}$ & 4 & PBS & 3 & 4.101 & 2.03 & 0.510 \\
\hline $10 \% 75 \mathrm{D} / \mathrm{SS}$ & 4 & PBS & 4 & 5.424 & 2.2 & 0.623 \\
\hline $10 \% 75 \mathrm{D} / \mathrm{SS}$ & 4 & PBS & 5 & 3.908 & 2.14 & 0.461 \\
\hline $10 \% 75 \mathrm{D} / \mathrm{SS}$ & 4 & PBS & 6 & 3.763 & 2.18 & 0.436 \\
\hline $10 \% \mathrm{PP} / \mathrm{SS}$ & 6 & $\mathrm{H} 2 \mathrm{O} 2$ & 1 & 2.978 & 2.64 & 0.285 \\
\hline $10 \% \mathrm{PP} / \mathrm{SS}$ & 6 & $\mathrm{H} 2 \mathrm{O} 2$ & 2 & 2.855 & 2.49 & 0.290 \\
\hline $10 \% \mathrm{PP} / \mathrm{SS}$ & 6 & $\mathrm{H} 2 \mathrm{O} 2$ & 3 & 3.07 & 2.03 & 0.382 \\
\hline $10 \% \mathrm{PP} / \mathrm{SS}$ & 6 & $\mathrm{H} 2 \mathrm{O} 2$ & 4 & 2.725 & 2.04 & 0.337 \\
\hline $10 \% \mathrm{PP} / \mathrm{SS}$ & 6 & $\mathrm{H} 2 \mathrm{O} 2$ & 5 & 2.275 & 2.12 & 0.271 \\
\hline $10 \% \mathrm{PP} / \mathrm{SS}$ & 6 & $\mathrm{H} 2 \mathrm{O} 2$ & 6 & 2.443 & 2.14 & 0.288 \\
\hline $10 \% \mathrm{PP} / \mathrm{SS}$ & 6 & PBS & 1 & 3.867 & 2.04 & 0.479 \\
\hline $10 \% \mathrm{PP} / \mathrm{SS}$ & 6 & PBS & 2 & 3.724 & 1.98 & 0.475 \\
\hline $10 \% \mathrm{PP} / \mathrm{SS}$ & 6 & PBS & 3 & 3.573 & 2.08 & 0.434 \\
\hline $10 \% \mathrm{PP} / \mathrm{SS}$ & 6 & PBS & 4 & 3.397 & 2.22 & 0.387 \\
\hline $10 \% \mathrm{PP} / \mathrm{SS}$ & 6 & PBS & 5 & 3.331 & 2.17 & 0.388 \\
\hline $10 \% \mathrm{PP} / \mathrm{SS}$ & 6 & PBS & 6 & 3.285 & 2.13 & 0.390 \\
\hline Silicone/SS & 6 & $\mathrm{H} 2 \mathrm{O} 2$ & 1 & 6.783 & 2.14 & 0.801 \\
\hline Silicone/SS & 6 & $\mathrm{H} 2 \mathrm{O} 2$ & 2 & 6.126 & 2.06 & 0.751 \\
\hline Silicone/SS & 6 & $\mathrm{H} 2 \mathrm{O} 2$ & 3 & 5.881 & 2.07 & 0.718 \\
\hline Silicone/SS & 6 & $\mathrm{H} 2 \mathrm{O} 2$ & 4 & 6.507 & 2.25 & 0.731 \\
\hline Silicone/SS & 6 & $\mathrm{H} 2 \mathrm{O} 2$ & 5 & 6.821 & 2.12 & 0.813 \\
\hline Silicone/SS & 6 & $\mathrm{H} 2 \mathrm{O} 2$ & 6 & 6.958 & 2.01 & 0.875 \\
\hline Silicone/SS & 6 & PBS & 1 & 6.01 & 2.34 & 0.649 \\
\hline
\end{tabular}




\begin{tabular}{|c|c|c|c|c|c|c|}
\hline Silicone/SS & 6 & PBS & 2 & 7.131 & 2.16 & 0.834 \\
\hline Silicone/SS & 6 & PBS & 3 & 7.269 & 2.23 & 0.823 \\
\hline Silicone/SS & 6 & PBS & 4 & 6.859 & 2.08 & 0.833 \\
\hline Silicone/SS & 6 & PBS & 5 & 6.473 & 2.02 & 0.810 \\
\hline Silicone/SS & 6 & PBS & 6 & 7.452 & 2.19 & 0.860 \\
\hline $10 \% 55 \mathrm{D} / \mathrm{SS}$ & 6 & $\mathrm{H} 2 \mathrm{O} 2$ & 1 & 3.778 & 2.43 & 0.393 \\
\hline $10 \% 55 \mathrm{D} / \mathrm{SS}$ & 6 & $\mathrm{H} 2 \mathrm{O} 2$ & 2 & 3.493 & 2.48 & 0.356 \\
\hline $10 \% 55 \mathrm{D} / \mathrm{SS}$ & 6 & $\mathrm{H} 2 \mathrm{O} 2$ & 3 & 3.585 & 2.11 & 0.429 \\
\hline $10 \% 55 \mathrm{D} / \mathrm{SS}$ & 6 & $\mathrm{H} 2 \mathrm{O} 2$ & 4 & 3.412 & 2.08 & 0.414 \\
\hline $10 \% 55 \mathrm{D} / \mathrm{SS}$ & 6 & $\mathrm{H} 2 \mathrm{O} 2$ & 5 & 3.492 & 2.36 & 0.374 \\
\hline $10 \% 55 \mathrm{D} / \mathrm{SS}$ & 6 & $\mathrm{H} 2 \mathrm{O} 2$ & 6 & 3.147 & 2.13 & 0.373 \\
\hline $10 \% 55 \mathrm{D} / \mathrm{SS}$ & 6 & PBS & 1 & 4.005 & 2.08 & 0.486 \\
\hline $10 \% 55 \mathrm{D} / \mathrm{SS}$ & 6 & PBS & 2 & 4.81 & 2.24 & 0.542 \\
\hline $10 \% 55 \mathrm{D} / \mathrm{SS}$ & 6 & PBS & 3 & 5.186 & 2.48 & 0.528 \\
\hline $10 \% 55 \mathrm{D} / \mathrm{SS}$ & 6 & PBS & 4 & 5.894 & 2.15 & 0.693 \\
\hline $10 \% 55 \mathrm{D} / \mathrm{SS}$ & 6 & PBS & 5 & 5.044 & 2.14 & 0.595 \\
\hline $10 \% 55 \mathrm{D} / \mathrm{SS}$ & 6 & PBS & 6 & 5.019 & 2.2 & 0.576 \\
\hline PIBS/SS & 6 & $\mathrm{H} 2 \mathrm{O} 2$ & 1 & 3.015 & 1.99 & 0.383 \\
\hline PIBS/SS & 6 & $\mathrm{H} 2 \mathrm{O} 2$ & 2 & 2.872 & 2.09 & 0.347 \\
\hline PIBS/SS & 6 & $\mathrm{H} 2 \mathrm{O} 2$ & 3 & 2.636 & 1.89 & 0.352 \\
\hline PIBS/SS & 6 & $\mathrm{H} 2 \mathrm{O} 2$ & 4 & 2.448 & 1.98 & 0.312 \\
\hline PIBS/SS & 6 & $\mathrm{H} 2 \mathrm{O} 2$ & 5 & 2.219 & 2.01 & 0.279 \\
\hline PIBS/SS & 6 & $\mathrm{H} 2 \mathrm{O} 2$ & 6 & 2.624 & 2.1 & 0.316 \\
\hline PIBS/SS & 6 & PBS & 1 & 3.198 & 2.31 & 0.350 \\
\hline PIBS/SS & 6 & PBS & 2 & 3.583 & 2.07 & 0.437 \\
\hline PIBS/SS & 6 & PBS & 3 & 3.369 & 2.15 & 0.396 \\
\hline PIBS/SS & 6 & PBS & 4 & 3.34 & 2.03 & 0.416 \\
\hline PIBS/SS & 6 & PBS & 5 & 3.124 & 2.01 & 0.393 \\
\hline PIBS/SS & 6 & PBS & 6 & 3.101 & 2.04 & 0.384 \\
\hline $10 \% 75 \mathrm{D} / \mathrm{SS}$ & 6 & $\mathrm{H} 2 \mathrm{O} 2$ & 1 & 3.026 & 2.07 & 0.369 \\
\hline $10 \% 75 \mathrm{D} / \mathrm{SS}$ & 6 & $\mathrm{H} 2 \mathrm{O} 2$ & 2 & 3.629 & 2.23 & 0.411 \\
\hline $10 \% 75 \mathrm{D} / \mathrm{SS}$ & 6 & $\mathrm{H} 2 \mathrm{O} 2$ & 3 & 4.498 & 2.21 & 0.514 \\
\hline $10 \% 75 \mathrm{D} / \mathrm{SS}$ & 6 & $\mathrm{H} 2 \mathrm{O} 2$ & 4 & 2.413 & 2.35 & 0.259 \\
\hline $10 \% 75 \mathrm{D} / \mathrm{SS}$ & 6 & $\mathrm{H} 2 \mathrm{O} 2$ & 5 & 3.512 & 2.25 & 0.394 \\
\hline $10 \% 75 \mathrm{D} / \mathrm{SS}$ & 6 & $\mathrm{H} 2 \mathrm{O} 2$ & 6 & 3.225 & 2.18 & 0.374 \\
\hline $10 \% 75 \mathrm{D} / \mathrm{SS}$ & 6 & PBS & 1 & 3.634 & 2.14 & 0.429 \\
\hline $10 \% 75 \mathrm{D} / \mathrm{SS}$ & 6 & PBS & 2 & 3.61 & 2.06 & 0.443 \\
\hline $10 \% 75 \mathrm{D} / \mathrm{SS}$ & 6 & PBS & 3 & 4.645 & 2.41 & 0.487 \\
\hline $10 \% 75 \mathrm{D} / \mathrm{SS}$ & 6 & PBS & 4 & 4.523 & 2.28 & 0.501 \\
\hline $10 \% 75 \mathrm{D} / \mathrm{SS}$ & 6 & PBS & 5 & 4.838 & 2.33 & 0.525 \\
\hline $10 \% 75 \mathrm{D} / \mathrm{SS}$ & 6 & PBS & 6 & 3.894 & 2.25 & 0.437 \\
\hline $10 \% \mathrm{PP} / \mathrm{SS}$ & 8 & $\mathrm{H} 2 \mathrm{O} 2$ & 1 & 1.975 & 2.09 & 0.239 \\
\hline $10 \% \mathrm{PP} / \mathrm{SS}$ & 8 & $\mathrm{H} 2 \mathrm{O} 2$ & 2 & 2.223 & 2.11 & 0.266 \\
\hline $10 \% \mathrm{PP} / \mathrm{SS}$ & 8 & $\mathrm{H} 2 \mathrm{O} 2$ & 3 & 2.828 & 1.97 & 0.363 \\
\hline $10 \% \mathrm{PP} / \mathrm{SS}$ & 8 & $\mathrm{H} 2 \mathrm{O} 2$ & 4 & 3.173 & 2.08 & 0.385 \\
\hline $10 \% \mathrm{PP} / \mathrm{SS}$ & 8 & $\mathrm{H} 2 \mathrm{O} 2$ & 5 & 2.43 & 2.14 & 0.287 \\
\hline $10 \% \mathrm{PP} / \mathrm{SS}$ & 8 & $\mathrm{H} 2 \mathrm{O} 2$ & 6 & 1.878 & 2.15 & 0.221 \\
\hline $10 \% \mathrm{PP} / \mathrm{SS}$ & 8 & PBS & 1 & 2.86 & 2.04 & 0.354 \\
\hline
\end{tabular}




\begin{tabular}{|c|c|c|c|c|c|c|}
\hline $10 \% \mathrm{PP} / \mathrm{SS}$ & 8 & PBS & 2 & 2.625 & 2.23 & 0.297 \\
\hline $10 \% \mathrm{PP} / \mathrm{SS}$ & 8 & PBS & 3 & 3.993 & 2.02 & 0.499 \\
\hline $10 \% \mathrm{PP} / \mathrm{SS}$ & 8 & PBS & 4 & 4.223 & 2.05 & 0.520 \\
\hline $10 \% \mathrm{PP} / \mathrm{SS}$ & 8 & PBS & 5 & 3.395 & 2.16 & 0.397 \\
\hline $10 \% \mathrm{PP} / \mathrm{SS}$ & 8 & PBS & 6 & 3.48 & 2.2 & 0.400 \\
\hline Silicone/SS & 8 & $\mathrm{H} 2 \mathrm{O} 2$ & 1 & 6.823 & 2.23 & 0.773 \\
\hline Silicone/SS & 8 & $\mathrm{H} 2 \mathrm{O} 2$ & 2 & 5.907 & 2.28 & 0.655 \\
\hline Silicone/SS & 8 & $\mathrm{H} 2 \mathrm{O} 2$ & 3 & 6.298 & 2.05 & 0.776 \\
\hline Silicone/SS & 8 & $\mathrm{H} 2 \mathrm{O} 2$ & 4 & 7.451 & 2.15 & 0.875 \\
\hline Silicone/SS & 8 & $\mathrm{H} 2 \mathrm{O} 2$ & 5 & 7.393 & 2.1 & 0.889 \\
\hline Silicone/SS & 8 & $\mathrm{H} 2 \mathrm{O} 2$ & 6 & 5.324 & 2.03 & 0.663 \\
\hline Silicone/SS & 8 & PBS & 1 & 7.371 & 2.09 & 0.891 \\
\hline Silicone/SS & 8 & PBS & 2 & 7.568 & 2.01 & 0.951 \\
\hline Silicone/SS & 8 & PBS & 3 & 6.167 & 2.28 & 0.683 \\
\hline Silicone/SS & 8 & PBS & 4 & 6.853 & 2.16 & 0.802 \\
\hline Silicone/SS & 8 & PBS & 5 & 6.705 & 2.13 & 0.795 \\
\hline Silicone/SS & 8 & PBS & 6 & 6.611 & 2.19 & 0.763 \\
\hline $10 \% 55 \mathrm{D} / \mathrm{SS}$ & 8 & $\mathrm{H} 2 \mathrm{O} 2$ & 1 & 2.792 & 2.03 & 0.347 \\
\hline $10 \% 55 \mathrm{D} / \mathrm{SS}$ & 8 & $\mathrm{H} 2 \mathrm{O} 2$ & 2 & 2.772 & 1.95 & 0.359 \\
\hline $10 \% 55 \mathrm{D} / \mathrm{SS}$ & 8 & $\mathrm{H} 2 \mathrm{O} 2$ & 3 & 2.81 & 2.18 & 0.326 \\
\hline $10 \% 55 \mathrm{D} / \mathrm{SS}$ & 8 & $\mathrm{H} 2 \mathrm{O} 2$ & 4 & 2.917 & 2.16 & 0.341 \\
\hline $10 \% 55 \mathrm{D} / \mathrm{SS}$ & 8 & $\mathrm{H} 2 \mathrm{O} 2$ & 5 & 2.803 & 2.21 & 0.320 \\
\hline $10 \% 55 \mathrm{D} / \mathrm{SS}$ & 8 & $\mathrm{H} 2 \mathrm{O} 2$ & 6 & 2.758 & 2.16 & 0.323 \\
\hline $10 \% 55 \mathrm{D} / \mathrm{SS}$ & 8 & PBS & 1 & 4.387 & 2.06 & 0.538 \\
\hline $10 \% 55 \mathrm{D} / \mathrm{SS}$ & 8 & PBS & 2 & 4.493 & 2.09 & 0.543 \\
\hline $10 \% 55 \mathrm{D} / \mathrm{SS}$ & 8 & PBS & 3 & 4.817 & 2.31 & 0.527 \\
\hline $10 \% 55 \mathrm{D} / \mathrm{SS}$ & 8 & PBS & 4 & 4.784 & 1.99 & 0.607 \\
\hline $10 \% 55 \mathrm{D} / \mathrm{SS}$ & 8 & PBS & 5 & 4.699 & 2.14 & 0.555 \\
\hline $10 \% 55 \mathrm{D} / \mathrm{SS}$ & 8 & PBS & 6 & 4.932 & 2.29 & 0.544 \\
\hline PIBS/SS & 8 & $\mathrm{H} 2 \mathrm{O} 2$ & 1 & 2.387 & 1.97 & 0.306 \\
\hline PIBS/SS & 8 & $\mathrm{H} 2 \mathrm{O} 2$ & 2 & 2.239 & 2.09 & 0.271 \\
\hline PIBS/SS & 8 & $\mathrm{H} 2 \mathrm{O} 2$ & 3 & 2.386 & 2 & 0.301 \\
\hline PIBS/SS & 8 & $\mathrm{H} 2 \mathrm{O} 2$ & 4 & 2.145 & 2.12 & 0.256 \\
\hline PIBS/SS & 8 & $\mathrm{H} 2 \mathrm{O} 2$ & 5 & 2.377 & 2.05 & 0.293 \\
\hline $\mathrm{PIBS} / \mathrm{SS}$ & 8 & $\mathrm{H} 2 \mathrm{O} 2$ & 6 & 2.694 & 2.06 & 0.330 \\
\hline PIBS/SS & 8 & PBS & 1 & 3.061 & 1.96 & 0.395 \\
\hline PIBS/SS & 8 & PBS & 2 & 2.451 & 2.07 & 0.299 \\
\hline PIBS/SS & 8 & PBS & 3 & 3.089 & 2.1 & 0.372 \\
\hline PIBS/SS & 8 & PBS & 4 & 3.803 & 2.07 & 0.464 \\
\hline PIBS/SS & 8 & PBS & 5 & 3.18 & 2.13 & 0.377 \\
\hline $\mathrm{PIBS} / \mathrm{SS}$ & 8 & PBS & 6 & 3.216 & 2.16 & 0.376 \\
\hline $10 \% 75 \mathrm{D} / \mathrm{SS}$ & 8 & $\mathrm{H} 2 \mathrm{O} 2$ & 1 & 2.572 & 2.22 & 0.293 \\
\hline $10 \% 75 \mathrm{D} / \mathrm{SS}$ & 8 & $\mathrm{H} 2 \mathrm{O} 2$ & 2 & 2.606 & 2.03 & 0.324 \\
\hline $10 \% 75 \mathrm{D} / \mathrm{SS}$ & 8 & $\mathrm{H} 2 \mathrm{O} 2$ & 3 & 3.895 & 2.52 & 0.390 \\
\hline $10 \% 75 \mathrm{D} / \mathrm{SS}$ & 8 & $\mathrm{H} 2 \mathrm{O} 2$ & 4 & 3.238 & 2.28 & 0.359 \\
\hline $10 \% 75 \mathrm{D} / \mathrm{SS}$ & 8 & $\mathrm{H} 2 \mathrm{O} 2$ & 5 & 3.386 & 2.17 & 0.394 \\
\hline $10 \% 75 \mathrm{D} / \mathrm{SS}$ & 8 & $\mathrm{H} 2 \mathrm{O} 2$ & 6 & 3.096 & 2.13 & 0.367 \\
\hline $10 \% 75 \mathrm{D} / \mathrm{SS}$ & 8 & PBS & 1 & 4.394 & 2.54 & 0.437 \\
\hline
\end{tabular}




\begin{tabular}{|l|l|l|l|l|l|l|}
$10 \% 75 \mathrm{D} / \mathrm{SS}$ & 8 & PBS & 2 & 4.894 & 3.01 & 0.411 \\
$10 \% 75 \mathrm{D} / \mathrm{SS}$ & 8 & PBS & 3 & 4.188 & 2.25 & 0.470 \\
$10 \% 75 \mathrm{D} / \mathrm{SS}$ & 8 & PBS & 4 & 3.873 & 2.21 & 0.443 \\
$10 \% 75 \mathrm{D} / \mathrm{SS}$ & 8 & PBS & 5 & 3.991 & 2.19 & 0.460 \\
$10 \% 75 \mathrm{D} / \mathrm{SS}$ & 8 & PBS & 6 & 4.194 & 2.28 & 0.465 \\
\hline
\end{tabular}




\begin{tabular}{|c|c|c|c|c|}
\hline Material Combination & $\begin{array}{c}\text { Treatment } \\
\text { Media }\end{array}$ & Aging (weeks) & $\begin{array}{l}\text { Bonding Shear } \\
\text { Strength } \\
\text { (MPA) }^{*}\end{array}$ & $\begin{array}{l}\text { Standard } \\
\text { Deviation }\end{array}$ \\
\hline $10 \% \mathrm{PP} / \mathrm{SS}$ & $\mathrm{H} 2 \mathrm{O} 2$ & $\overline{0}$ & 0.431 & 0.090 \\
\hline $10 \% \mathrm{PP} / \mathrm{SS}$ & $\mathrm{H} 2 \mathrm{O} 2$ & 2 & 0.375 & 0.046 \\
\hline $10 \% \mathrm{PP} / \mathrm{SS}$ & $\mathrm{H} 2 \mathrm{O} 2$ & 4 & 0.310 & 0.086 \\
\hline $10 \% \mathrm{PP} / \mathrm{SS}$ & $\mathrm{H} 2 \mathrm{O} 2$ & 6 & 0.309 & 0.042 \\
\hline $10 \% \mathrm{PP} / \mathrm{SS}$ & $\mathrm{H} 2 \mathrm{O} 2$ & 8 & 0.293 & 0.067 \\
\hline $10 \% \mathrm{PP} / \mathrm{SS}$ & PBS & 0 & 0.431 & 0.090 \\
\hline $10 \% \mathrm{PP} / \mathrm{SS}$ & PBS & 2 & 0.396 & 0.050 \\
\hline $10 \% \mathrm{PP} / \mathrm{SS}$ & PBS & 4 & 0.385 & 0.023 \\
\hline $10 \% \mathrm{PP} / \mathrm{SS}$ & PBS & 6 & 0.425 & 0.044 \\
\hline $10 \% \mathrm{PP} / \mathrm{SS}$ & PBS & 8 & 0.411 & 0.085 \\
\hline Silicone/SS & $\mathrm{H} 2 \mathrm{O} 2$ & 0 & 0.785 & 0.111 \\
\hline Silicone/SS & $\mathrm{H} 2 \mathrm{O} 2$ & 2 & 0.860 & 0.112 \\
\hline Silicone/SS & $\mathrm{H} 2 \mathrm{O} 2$ & 4 & 0.878 & 0.101 \\
\hline Silicone/SS & $\mathrm{H} 2 \mathrm{O} 2$ & 6 & 0.781 & 0.059 \\
\hline Silicone/SS & $\mathrm{H} 2 \mathrm{O} 2$ & 8 & 0.772 & 0.100 \\
\hline Silicone/SS & PBS & 0 & 0.785 & 0.111 \\
\hline Silicone/SS & PBS & 2 & 0.837 & 0.086 \\
\hline Silicone/SS & PBS & 4 & 0.835 & 0.105 \\
\hline Silicone/SS & PBS & 6 & 0.801 & 0.077 \\
\hline Silicone/SS & PBS & 8 & 0.814 & 0.095 \\
\hline $10 \% 55 \mathrm{D} / \mathrm{SS}$ & $\mathrm{H} 2 \mathrm{O} 2$ & 0 & 0.560 & 0.036 \\
\hline $10 \% 55 \mathrm{D} / \mathrm{SS}$ & $\mathrm{H} 2 \mathrm{O} 2$ & 2 & 0.521 & 0.062 \\
\hline $10 \% 55 \mathrm{D} / \mathrm{SS}$ & $\mathrm{H} 2 \mathrm{O} 2$ & 4 & 0.479 & 0.029 \\
\hline $10 \% 55 \mathrm{D} / \mathrm{SS}$ & $\mathrm{H} 2 \mathrm{O} 2$ & 6 & 0.390 & 0.028 \\
\hline $10 \% 55 \mathrm{D} / \mathrm{SS}$ & $\mathrm{H} 2 \mathrm{O} 2$ & 8 & 0.336 & 0.016 \\
\hline $10 \% 55 \mathrm{D} / \mathrm{SS}$ & PBS & 0 & 0.560 & 0.036 \\
\hline $10 \% 55 \mathrm{D} / \mathrm{SS}$ & PBS & 2 & 0.550 & 0.043 \\
\hline $10 \% 55 \mathrm{D} / \mathrm{SS}$ & PBS & 4 & 0.559 & 0.029 \\
\hline $10 \% 55 \mathrm{D} / \mathrm{SS}$ & PBS & 6 & 0.570 & 0.071 \\
\hline $10 \% 55 \mathrm{D} / \mathrm{SS}$ & PBS & 8 & 0.552 & 0.028 \\
\hline PIBS/SS & $\mathrm{H} 2 \mathrm{O} 2$ & 0 & 0.407 & 0.048 \\
\hline PIBS/SS & $\mathrm{H} 2 \mathrm{O} 2$ & 2 & 0.363 & 0.052 \\
\hline PIBS/SS & $\mathrm{H} 2 \mathrm{O} 2$ & 4 & 0.372 & 0.059 \\
\hline PIBS/SS & $\mathrm{H} 2 \mathrm{O} 2$ & 6 & 0.332 & 0.037 \\
\hline PIBS/SS & $\mathrm{H} 2 \mathrm{O} 2$ & 8 & 0.293 & 0.027 \\
\hline PIBS/SS & PBS & 0 & 0.407 & 0.048 \\
\hline PIBS/SS & PBS & 2 & 0.400 & 0.079 \\
\hline PIBS/SS & PBS & 4 & 0.385 & 0.023 \\
\hline PIBS/SS & PBS & 6 & 0.396 & 0.030 \\
\hline PIBS/SS & PBS & 8 & 0.380 & 0.053 \\
\hline $10 \% 75 \mathrm{D} / \mathrm{SS}$ & $\mathrm{H} 2 \mathrm{O} 2$ & 0 & 0.513 & 0.066 \\
\hline $10 \% 75 \mathrm{D} / \mathrm{SS}$ & $\mathrm{H} 2 \mathrm{O} 2$ & 2 & 0.480 & 0.029 \\
\hline $10 \% 75 \mathrm{D} / \mathrm{SS}$ & $\mathrm{H} 2 \mathrm{O} 2$ & 4 & 0.418 & 0.065 \\
\hline $10 \% 75 \mathrm{D} / \mathrm{SS}$ & $\mathrm{H} 2 \mathrm{O} 2$ & 6 & 0.387 & 0.082 \\
\hline $10 \% 75 \mathrm{D} / \mathrm{SS}$ & $\mathrm{H} 2 \mathrm{O} 2$ & 8 & 0.355 & 0.039 \\
\hline $10 \% 75 \mathrm{D} / \mathrm{SS}$ & PBS & 0 & 0.513 & 0.066 \\
\hline $10 \% 75 \mathrm{D} / \mathrm{SS}$ & PBS & 2 & 0.501 & 0.034 \\
\hline $10 \% 75 \mathrm{D} / \mathrm{SS}$ & PBS & 4 & 0.510 & 0.078 \\
\hline $10 \% 75 \mathrm{D} / \mathrm{SS}$ & PBS & 6 & 0.470 & 0.039 \\
\hline $10 \% 75 \mathrm{D} / \mathrm{SS}$ & PBS & 8 & 0.448 & 0.022 \\
\hline
\end{tabular}

